\title{
Tropical tree growth sensitivity to climate is driven by species intrinsic growth rate and leaf traits
}

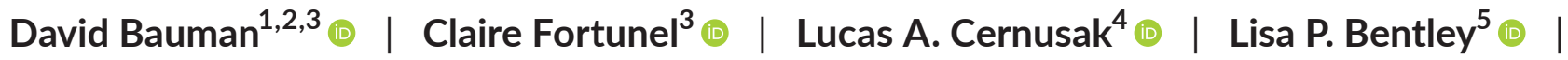

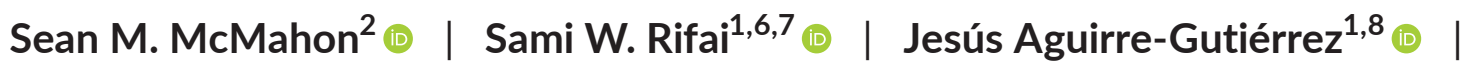

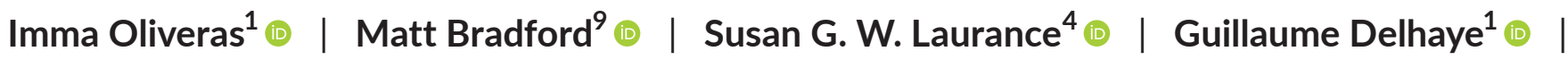

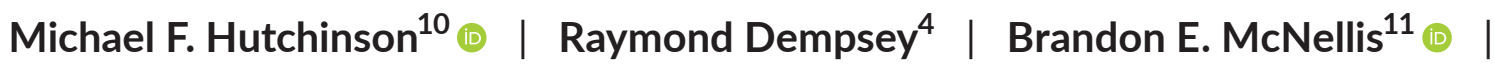 \\ Paul E. Santos-Andrade ${ }^{12}$ @ | Hugo R. Ninantay-Rivera ${ }^{12}$ | Jimmy R. Chambi Paucar ${ }^{12}$ | \\ Oliver L. Phillips ${ }^{13}$ () $\mid$ Yadvinder Malhi ${ }^{1}$ (1) \\ ${ }^{1}$ Environmental Change Institute, School of Geography and the Environment, University of Oxford, Oxford, UK \\ ${ }^{2}$ Smithsonian Environmental Research Center, Edgewater, Maryland, USA \\ ${ }^{3}$ AMAP (Botanique et Modélisation de l'Architecture des Plantes et des Végétations), Université de Montpellier, CIRAD, CNRS, INRAE, IRD, Montpellier, France \\ ${ }^{4}$ Centre for Tropical Environmental and Sustainability Science, College of Science and Engineering, James Cook University, Cairns, Queensland, Australia \\ ${ }^{5}$ Department of Biology, Sonoma State University, Rohnert Park, California, USA \\ ${ }^{6}$ ARC Centre of Excellence for Climate Extremes, University of New South Wales, Sydney, New South Wales, Australia \\ ${ }^{7}$ Department of Environmental Science, Policy and Management, UC Berkeley, Berkeley, California, USA \\ ${ }^{8}$ Biodiversity Dynamics, Naturalis Biodiversity Center, Leiden, The Netherlands \\ ${ }^{9} \mathrm{CSIRO}$ Land and Water, Tropical Forest Research Centre, Atherton, Queensland, Australia \\ ${ }^{10}$ Fenner School of Environment and Society, The Australian National University, Canberra, Australia \\ ${ }^{11}$ Department of Plant and Environmental Sciences, New Mexico State University, Las Cruces, New Mexico, USA \\ ${ }^{12}$ Universidad Nacional San Antonio Abad del Cusco, Cusco, Perú \\ ${ }^{13}$ School of Geography, University of Leeds, Leeds, UK
}

\section{Correspondence}

David Bauman, Environmental Change Institute, School of Geography and the Environment, University of Oxford, Oxford, UK.

Email: david.bauman@oxfordecosystems. co.uk

Funding information

Fondation Philippe Wiener - Maurice Anspach; Belgian American Educational Foundation; H2020 European Research Council, Grant/Award Number: 291585; Frank Jackson Foundation; Natural Environment Research Council, Grant/ Award Number: NE/P001092/1

\begin{abstract}
A better understanding of how climate affects growth in tree species is essential for improved predictions of forest dynamics under climate change. Long-term climate averages (mean climate) drive spatial variations in species' baseline growth rates, whereas deviations from these averages over time (anomalies) can create growth variation around the local baseline. However, the rarity of long-term tree census data spanning climatic gradients has so far limited our understanding of their respective role, especially in tropical systems. Furthermore, tree growth sensitivity to climate is likely to vary widely among species, and the ecological strategies underlying these differences remain poorly understood. Here, we utilize an exceptional dataset of 49 years of growth data for 509 tree species across 23 tropical rainforest plots along a climatic gradient to examine how multiannual tree growth responds to both climate means and anomalies, and how species' functional traits mediate these growth
\end{abstract}


responses to climate. We show that anomalous increases in atmospheric evaporative demand and solar radiation consistently reduced tree growth. Drier forests and fastgrowing species were more sensitive to water stress anomalies. In addition, species traits related to water use and photosynthesis partly explained differences in growth sensitivity to both climate means and anomalies. Our study demonstrates that both climate means and anomalies shape tree growth in tropical forests and that species traits can provide insights into understanding these demographic responses to climate change, offering a promising way forward to forecast tropical forest dynamics under different climate trajectories.

\section{KEYWORDS}

climate anomalies, climate change, demography, fast-slow continuum, functional traits, photosynthesis, tree vital rates, tropical moist forest ecology, vapour pressure deficit (VPD), water use efficiency

\section{1 | INTRODUCTION}

Tropical forests are key contributors to global carbon sequestration (Needham et al., 2018; Pan et al., 2011), but climate change may reduce this important ecosystem service by suppressing tree growth or increasing mortality, particularly in tropical forests (Brodribb et al., 2020; Sullivan et al., 2020). Therefore, it is important to understand how climate influences tree growth, both through long-term local averages (hereafter, 'mean climate', calculated over a period of 30 years in climate science) and deviations from these averages in a given location over a given time period (hereafter, anomalies) (Harris et al., 2018; Jentsch et al., 2007; Malhi et al., 2009; Rifai et al., 2018, 2019). Long-term mean climate can constrain the ways species achieve different baseline growth rates (hereafter intrinsic growth rates) in different locations through their effect on tree physiological processes (Green et al., 2019; Rifai et al., 2018; Sullivan et al., 2020), while climate anomalies can also drive growth rate deviations from the local baseline at a range of temporal scales, including days (Zweifel et al., 2021), months (Clark, 2003; Mendivelso et al., 2014; Rifai et al., 2018, 2019), and multiple years (Coomes et al., 2014; Mendivelso et al., 2014; Rohner et al., 2018; Uriarte et al., 2016; Yuan et al., 2019). The multiannual scale of growth variation is of particular interest in the context of climate change; growth changes over long periods that include sustained periods of constraining climatic anomalies (with less opportunity for recovery) likely reflect tree performance responses that impact long-term forest dynamics with climate change (Harris et al., 2018; Jentsch et al., 2007; Sanginés de Cárcer et al., 2018; Yuan et al., 2019). Evidence of such multiannual climate anomaly effects include growth reduction in tropical dry forests following high dry season atmospheric water demand (Mendivelso et al., 2014; Uriarte et al., 2016), or the negative effect of high water deficit on stem net primary productivity (Rifai et al., 2018).

Major difficulties to disentangle the effects of mean climate and anomalies on spatial and temporal growth variations across species in wet tropical forests include the high species diversity in this biome, the common lack of annual growth rings (Brienen et al., 2016) and the potentially wide range of species growth sensitivities to climate (e.g. DeSoto et al., 2020; Mendivelso et al., 2014; Sanginés de Cárcer et al., 2018; Uriarte et al., 2016). Addressing these challenges requires simultaneously studying multiple sites with different baseline mean climates that share common species. Consequently, we still have a limited understanding of the mechanisms responsible for species differences in their growth sensitivity to climate means and anomalies. Functional traits (sensu Violle et al., 2007) can capture species differences in ecological strategies and allocation tradeoffs to growth, survival and reproduction (McGill et al., 2006; Westoby et al., 2002), and can offer a path towards a more mechanistic insight into the ecological strategies underlying tree growth response to climate drivers (Brodribb et al., 2020; Laughlin et al., 2020; Uriarte et al., 2016; Wagner et al., 2014; Zambrano et al., 2017). Specifically, the 'fast-slow' plant economics spectrum links fast-growing and slow-growing species to acquisitive and conservative trait values, respectively (Reich, 2014). As high intrinsic growth rates may come with a cost of lower stress tolerance (Gibert et al., 2016; Reich, 2014), acquisitive strategies could be associated with increased growth sensitivity to climate anomalies, while conservative strategies could attenuate it. Physiological traits directly related to photosynthesis and water use efficiency, in particular, are good candidates to reflect the effects of light- and water-related climate variables on tree growth and forest dynamics (Brodribb et al., 2020; Powers et al., 2020; Rowland et al., 2021; Wagner et al., 2014).

Further, where species perform better (eg, grow faster) across a range of mean climatic conditions may also underlie different ecological strategies and help predict expected performance sensitivities to climatic anomalies (eg, drier periods). However, the sign of this relation remains unclear, as species with long-term adaptations to a constraining climatic condition (eg, drier mean climate) may be either better adapted or closer to a threshold with respect to further deviations (Aguirre-Gutiérrez et al., 2019, 2020; Bennett et al., 2021; Esquivel-Muelbert et al., 2020; Zuleta et al., 2017). A related uncertainty when scaling up from the species to the forest level is whether 
growth sensitivity to climate anomalies varies overall depending on local mean climate. Recent works point to additive or interacting effects between mean climate or climate trends and climate anomalies of increasing magnitude and intensity on ecosystem functions and organisms responses to climate change (Aguirre-Gutiérrez et al., 2019, 2020; Harris et al., 2018; Sullivan et al., 2020), but whether the productivity of tropical forests is more at risk in relatively drier or warmer mean conditions remains little understood, in the face of a further increase in temperature and atmospheric water demand related to global warming (Grossiord et al., 2020; Harris et al., 2018; Sullivan et al., 2020; Yuan et al., 2019).

Here, we take advantage of a unique 49-year dataset of regularly censused tropical tree growth (two- to five-year intervals) spanning 509 species across 23 plots covering an elevation range of $1200 \mathrm{~m}$ and encompassing a broad range of climatic conditions, in North Queensland (Wet Tropics of Australia). We additionally use 15 morphological, chemical, and physiological traits related to leaf, wood, and maximum size collected within the plot network for 75 dominant species to test how these traits mediate species growth responses to climate drivers. We couple the multi-year census data with the detailed plant traits dataset in Bayesian hierarchical models to relate tree growth to species traits, forest plots, and climate (Figure 1). We examine the effects of both mean climate and climate anomalies on interannual tree growth variation, both within and across species, and evaluate the role of functional traits in capturing species differences in growth sensitivity. We also test whether the effects of climate anomalies on plot-level growth rate variation depend upon long-term mean climate. Specifically, we ask:

(a)

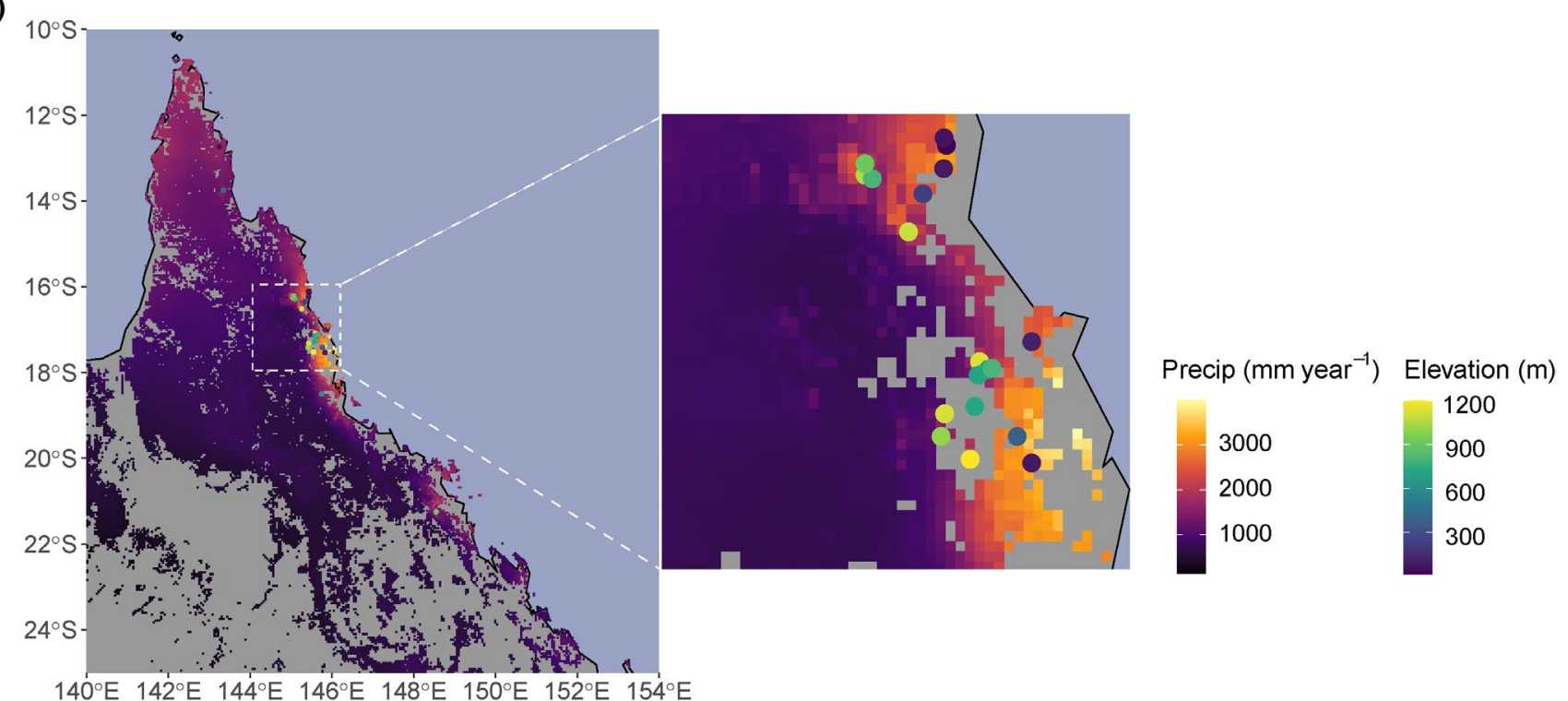

Mean climate (1981-2010) and anomalies of VPD and solar radiation
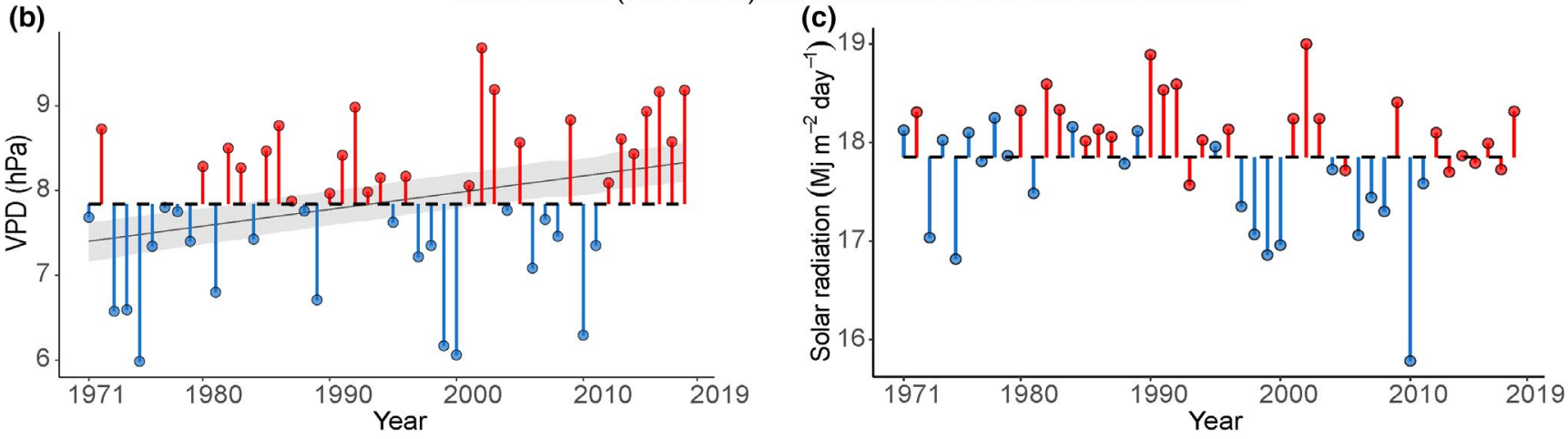

FIGURE 1 Spatial and temporal dimensions of the tropical forest network. (a) Maps of North Queensland (Australia) and the 23 forest plots on a background of the long-term mean annual precipitation for woody vegetation areas. Circles: plots; Circle colours: Plot elevation (strongly negatively correlated to mean annual temperature, Table S3a). (b, c) Illustration of the temporal extent of the study and of the concepts of mean climate and anomalies for one plot (Mont Haig) presenting vapour pressure deficit (VPD) and solar radiation (SRAD) through time, respectively. (b, c) Show the mean climate (1981-2010) (horizontal black dashed line) and negative and positive anomalies (blue and red vertical segments and dots; monthly anomalies averaged per year). VPD and SRAD were modelled as a plot-specific function of year (see Section 2 and Table S4). The thin black line and shaded areas are the median and 95\%-highest posterior density interval (HPDI) of the slope characterising the VPD increase over time. SRAD did not present any clear trend (slope not represented; i.e. the 95\%-HPDI encompassed zero) 
1. How do mean climate and climate anomalies determine interannual variation in tree growth rates, and what are the main climatic drivers?

2. Are species that grow faster in drier locations more resistant to water stress anomalies?

3. Can intrinsic growth rate and functional traits explain interspecific differences in growth sensitivities to climate?

4. Are drier and warmer forests more sensitive to positive anomalies in temperature and water stress?

\section{2 | MATERIALS AND METHODS}

\section{1 | Study sites and demographic data}

Individual tree annual absolute growth rates were calculated for 12,853 trees in 23 permanent forest plots of tropical rainforest located in northern Queensland, Australia, between $12^{\circ} 44^{\prime} \mathrm{S}$ to $21^{\circ} 15^{\prime} \mathrm{S}$ and $143^{\circ} 15^{\prime} \mathrm{E}$ to $148^{\circ} 33^{\prime} \mathrm{E}$, and encompassing an elevation gradient between 15 and $1200 \mathrm{~m}$ a.s.l. and a period of 49 years (Figure 1a; Table S1) (20 CSIRO long-term plots (Bradford et al., 2014), and three more recent plots; see Supplementary Methods S1). Regular cyclonic disturbance contributes to the dynamics of the forests (Murphy et al., 2013). They cover a wide range of mean annual temperatures (19 to $26.1^{\circ} \mathrm{C}$ ), precipitations (1213 to $3563 \mathrm{~mm}$ ), solar radiation (17.8-19.4 $\mathrm{MJ} \mathrm{m}^{-2} \mathrm{day}^{-1}$ ) and vapour pressure deficit (VPD, 6.5-11.8 hPa) (Table S1). At plot establishment, all trees with stems $\geq 10 \mathrm{~cm}$ diameter at breast height ( $\mathrm{DBH}$ ) were mapped, identified to species level and measured for diameter. The 20 longterm plots were re-measured every 2 years for 10 years, and then at three- to four-year intervals, with diameter, recruits and deaths recorded, summing up to 11-17 censuses per plot. The remaining three plots were established between 2001 and 2012 and resampled one to three times (Table S1).

All available censuses were used to calculate individual annualized absolute growth rate (AGR) based on DBH at date 1 and $2\left(t_{1}\right.$ and $t_{2}$ ), as:

$$
\mathrm{AGR}=\frac{\mathrm{DBH} \mathrm{t}_{2}-\mathrm{DBH}_{t_{1}}}{(\mathrm{nb} \text { days })_{t_{2}-t_{1}}} \times 365
$$

Abnormal AGR values were removed following Condit et al. (2004; see Supplementary Methods S1). Pteridophytes and palms species were excluded from the analyses due to their lack of secondary growth.

\section{2 | Climate data}

The effect of climate on growth was studied through four climate variables encompassing a wide range of variability across the plots and relevant for tree growth (see details in Supplementary Methods S1): mean temperature $\left(T_{\text {mean }}\right)$, solar radiation (SRAD), VPD, and maximum climatological water deficit (MCWD; a proxy of the annual accumulated water stress over the drier season, estimated from climate data as the cumulative deficit between precipitation and evapotranspiration; hence, better capturing the seasonality of precipitation and potential soil water deficit than precipitation (Aragão et al., 2007; Malhi et al., 2009, 2015) (Tables S1 and S3a).

Climate data collection is detailed in the Supplementary Methods S1 and summarized here. Monthly climatic variables were obtained for the period 1970 to 2018 for each plot from ANUClimate v.2.0 (Hutchinson et al., 2014), a spatial model constructed from a new anomaly-based approach to the interpolation of Australia's national point climate data to produce climate variables on a $0.01^{\circ}$ longitude-latitude grid. The monthly climate variables were interpolated from the standard Bureau of Meteorology data network using elevation-dependent thin plate smoothing splines as calculated by the ANUSPLIN package (Hutchinson \& Xu, 2013). The elevation dependence of these analyses yielded acceptably small predictive errors. Maximum and minimum temperatures were estimated with mean absolute predictive errors of around $0.5^{\circ} \mathrm{C}$ and solar radiation, VPD and rainfall were estimated with relative mean absolute predictive errors of $4 \%, 7 \%$ and $18 \%$, respectively. The monthly actual evapotranspiration $\left(a_{\mathrm{et}}\right)$ was derived from TerraClimate (Abatzoglou et al., 2018). The $a_{\mathrm{et}}$ was used in combination with rainfall to calculate the monthly climatological water deficit (CWD). The CWD was reset to zero at the wettest month of the year and had an upper bound at $1000 \mathrm{~mm}$. It was used to calculate monthly MCWD through a rolling maximum over the previous 12 months.

In each forest plot, a monthly 30-year historical mean and standard deviation were calculated over the 1981-2010 period for $T_{\text {mean }}$, SRAD, VPD, and MCWD (Table S1). On this basis, we calculated in each plot the monthly anomalies for each variable (i.e., monthly 30 year mean $\mu$ subtracted from monthly value) and divided them by their location-specific 30-year monthly standard deviation $\sigma$, yielding standardized anomalies (Aragão et al., 2007; Rifai et al., 2018):

$$
\text { anomaly_std }_{k, t}=\frac{\left(X_{k, t}-\mu_{k}\right)}{\sigma_{k}} \text {, }
$$

where $X_{k, t}$ is the climate variable value in plot $k$ at time $t$ (i.e., year and month), and $\mu_{k}$ and $\sigma_{k}$ are the monthly 30-year mean and standard deviation of the corresponding plot.

Standardized anomalies are expressed in units of standard deviation from monthly means over 1981-2010. This allows the comparison of plots differing not only in their historical means but also in the long-term variation range around them, that is, an important element to detect anomaly effects on tree growth across different climates (Rifai et al., 2018).

To build the climate covariates for the tree growth models, the monthly 30-year mean and standardized anomaly variables were averaged over the months between consecutive censuses (2-5 years). For MCWD, the maximum over the growth periods between two censuses was used instead of the weighted mean. The eight resulting interannual averaged variables were used as predictors to model 
tree growth (see Section 2.5). Correlations among these variables, stand structure, and elevation are presented in Table S3a and the Supplementary Methods S1.

\section{3 | Stand structure}

As stand structure can vary between plots, we include its effect on tree growth through total plot basal area. Plot basal area $\left(\mathrm{m}^{2} \mathrm{ha}^{-1}\right)$ was calculated at each census, with expectations that increasing basal area would have a general negative effect on tree growth (Muledi et al., 2020; Sánchez-Salguero et al., 2015).

\subsection{Functional traits}

Between July and September 2015, we measured 15 traits of 75 dominants, canopy tree species in eight plots along the gradient (Table 1; Tables S1 and S2) for plot and species details. Species were chosen to sample those that made up $80 \%$ of the standing biomass in these eight plots, but were also present in varying proportions in other plots; hence, covering the climatic range of the plot network. Trait data collection and measurement are detailed in Supplementary Methods S1. We measured leaf, wood, and maximum size traits that relate to light, water and nutrient use (Table 1; see Table S3b for pairwise trait correlations, and Figure S1 for trait distribution along the elevation gradient). Traits were measured on three individuals per species and included photosynthesis and stomatal conductance at a reference $\mathrm{CO}_{2}$ concentration of $400 \mu \mathrm{mol} \mathrm{mol}{ }^{-1}$ and irradiance of $1500 \mu \mathrm{mol}$ photons $\mathrm{m}^{-2} \mathrm{~s}^{-1}\left(A_{\text {sat }}\right.$ and $g_{\text {sat }}$ ), dark respiration $\left(R_{\mathrm{d}}\right)$ at the same $\mathrm{CO}_{2}$ concentration, the $\mathrm{CO}_{2}$-saturated photosynthesis and stomatal conductance $\left(A_{\max }\right.$ and $\left.g_{\max }\right)$, measured at $1200 \mu \mathrm{mol} \mathrm{mol}{ }^{-1} \mathrm{CO}_{2}$. The one-point method (De Kauwe et al., 2016) was used to estimate the maximum carboxylation rate $\left(V_{\text {cmax }}\right)$ for each individual from net photosynthesis measured at $400 \mu \mathrm{mol} \mathrm{mol}{ }^{-1} \mathrm{CO}_{2}$, and maximum light-driven electron flux $\left(J_{\max }\right)$ from net photosynthesis measured at $1200 \mu \mathrm{mol} \mathrm{mol}{ }^{-1} \mathrm{CO}_{2}$ (Bloomfield et al., 2018) (see Supplementary Methods S1 for correlation of one-point estimates and Aci curve-derived $J_{\max }$ and $V_{c \max }$ of a subset of species). We also measured leaf stable carbon isotope ratio $\left(\delta^{13} \mathrm{C}\right)$, nutrient concentration, and leaf area, leaf mass per area (LMA), leaf thickness, and wood density (from branches, after bark removal). All traits were averaged at the species level for tree growth analyses.

\section{5 | Data analysis}

We addressed our four questions through three sets of Bayesian multilevel models (M1 to M3; details in Supplementary Methods S1).

\subsection{1 | M1: Tree growth response to climate} means and anomalies, and species differences in their sensitivities to climate

In the M1 models, we used 12,853 individuals from all 509 species to test the effects of climate on tree growth and to investigate tradeoffs among species between intrinsic growth rate and growth sensitivity to climate covariates (ie, to address question 1). We built a two-level hierarchical Bayesian model of AGR, where the hierarchy included an upper level of response (hereafter grand coefficients or effects, affecting AGR across species) above a lower, species-level response. The higher level modelled AGR responses to covariates via hyperparameters (i.e., statistical distributions from which specieslevel intercepts and slope coefficients arose), while the lower level captured species-specific growth sensitivities to model covariates, and species-level intercepts (hereafter intrinsic AGR) captured unexplained growth variation across individuals, growth periods, and plots.

More specifically, we modelled individual $\log (A G R)$ as a speciesspecific function of (i) initial tree size (approximated by $\log (\mathrm{DBH})$ at the beginning of a growth period), (ii) the local 30-year mean of a climate variable, (iii) the anomalies of the same climate variable averaged over the studied growth period, and (iv) stand structure (approximated by plot basal area at the beginning of a growth period), using varying slopes (also known as random slopes) and a covariance matrix to estimate correlations among species-specific AGR sensitivities to the covariates, as:

$$
\log \left(\mathrm{AGR}_{\mathrm{i}, \mathrm{j}, \mathrm{k}, \mathrm{t}}\right) \sim \operatorname{Normal}\left(\mu_{\mathrm{i}, \mathrm{j}, \mathrm{k}, \mathrm{t}}, \sigma_{R}\right) \quad \text { [Likelihood] }
$$

$$
\begin{aligned}
\mu_{i, j, k, t}= & \alpha_{j}+\beta_{1 j} \times \log \left(\mathrm{DBH}_{i, t}\right)+\beta_{2 j} \times \operatorname{meanClim}_{k}+\beta_{3 j} \\
& \times \operatorname{climAnom}_{k, t}+\beta_{4 j} \times \mathrm{BA}_{k, t}+\gamma_{k}+\delta_{t}+\lambda_{i} \quad[\text { Linear model }],
\end{aligned}
$$

$$
\left(\begin{array}{c}
\alpha_{j} \\
\beta_{1 j} \\
\vdots \\
\beta_{4 j}
\end{array}\right) \sim \text { MVNormal }\left(\begin{array}{c}
\alpha_{0} \\
\beta_{1,0} \\
\vdots \\
\beta_{4,0}
\end{array}\right) \text { [Adaptive priors for species - level param.] }
$$

$$
S=\left(\begin{array}{cccc}
\sigma_{\alpha} & 0 & 0 & 0 \\
0 & \sigma_{\beta_{1}} & 0 & 0 \\
\vdots & \vdots & \ddots & \vdots \\
0 & 0 & 0 & \sigma_{\beta_{4}}
\end{array}\right) R\left(\begin{array}{cccc}
\sigma_{\alpha} & 0 & 0 & 0 \\
0 & \sigma_{\beta_{1}} & 0 & 0 \\
\vdots & \vdots & \ddots & \vdots \\
0 & 0 & 0 & \sigma_{\beta_{4}}
\end{array}\right)
$$

[Construction of covariance matrix], 

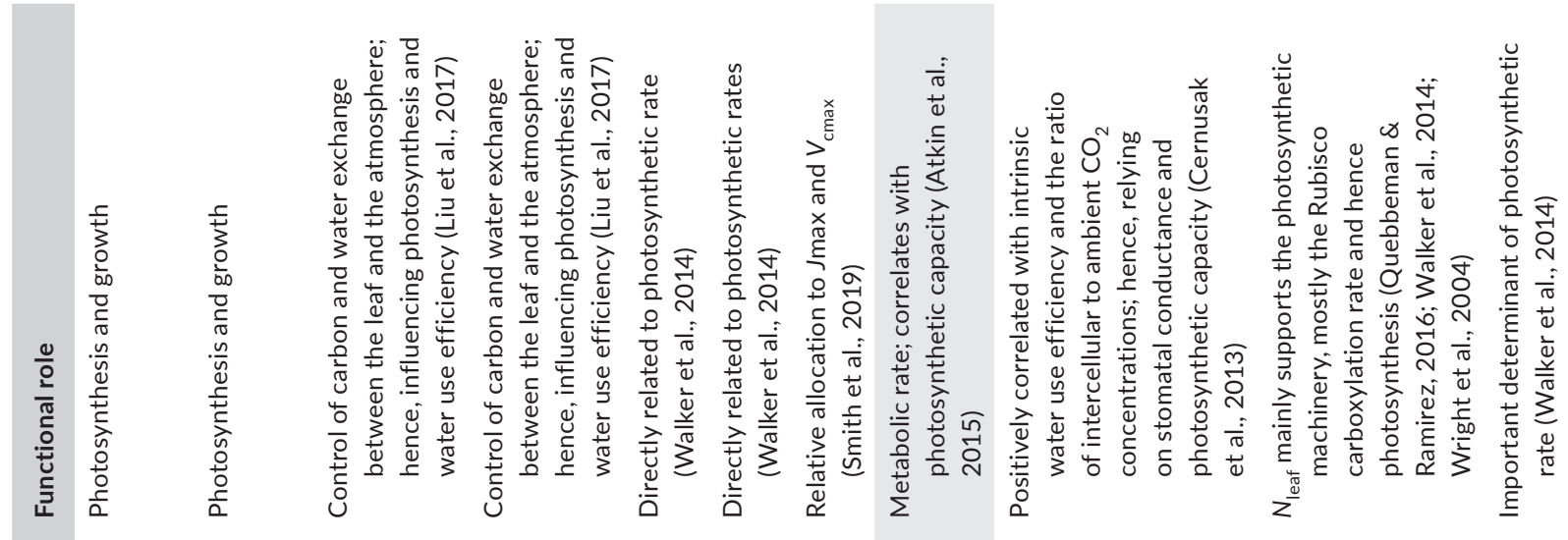

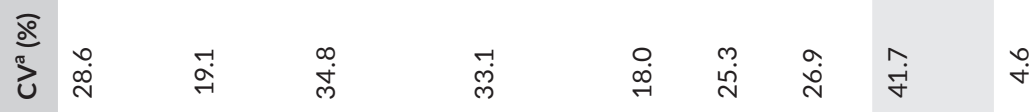

$\stackrel{\text { ஸ̊ }}{\mathrm{N}}$

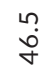

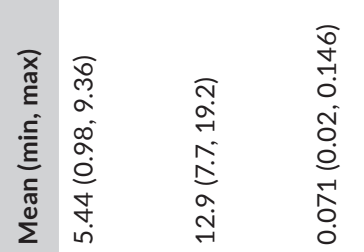

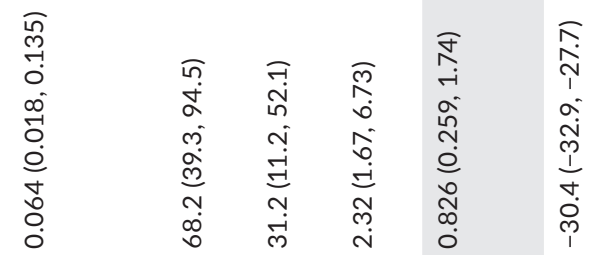

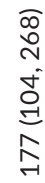

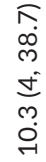

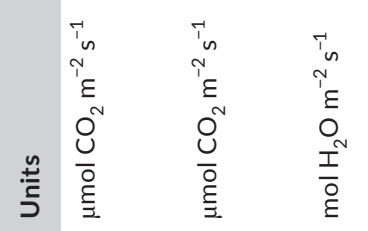

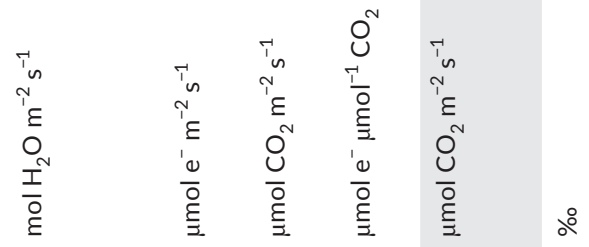

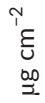

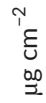

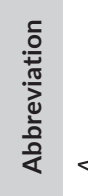

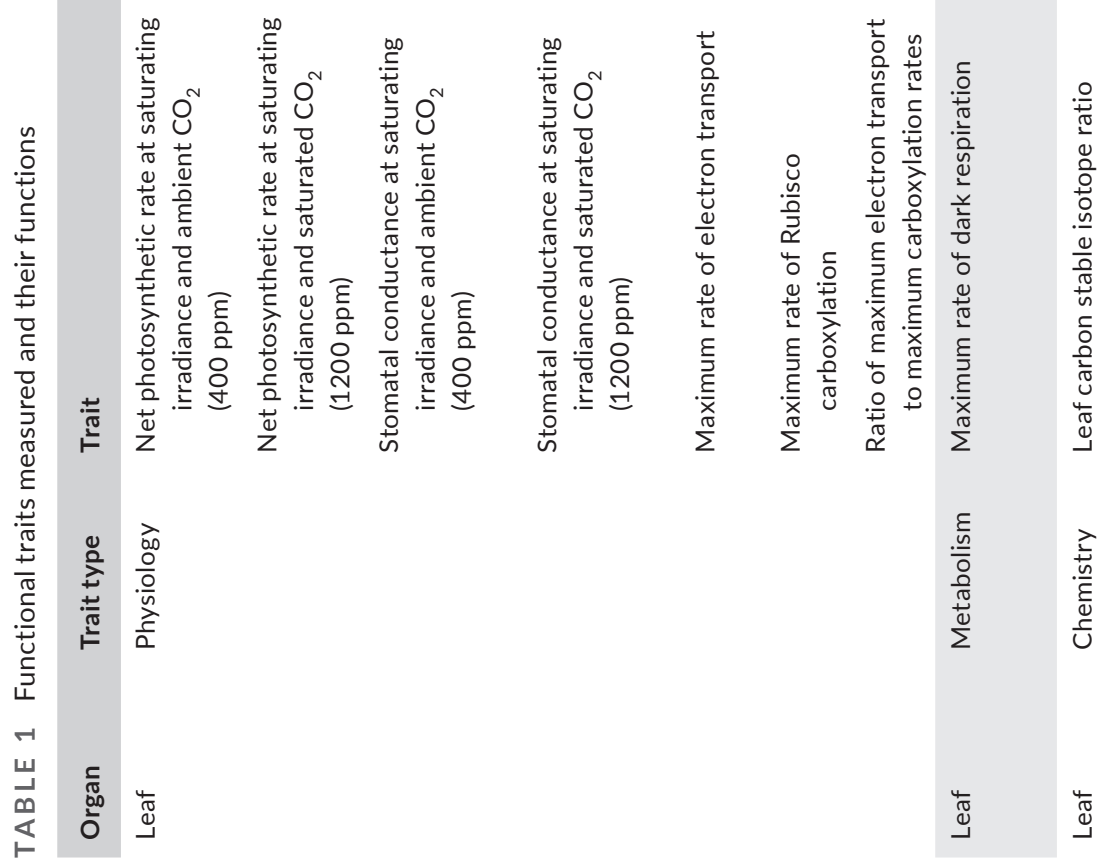




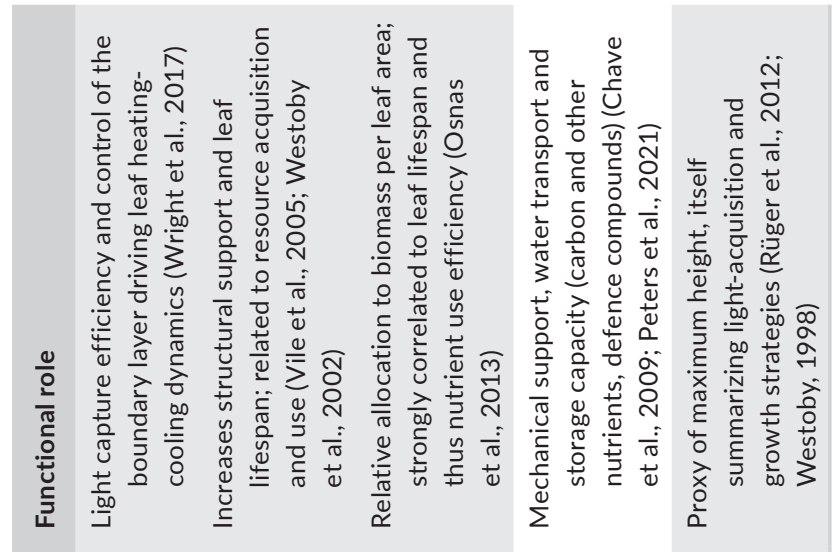

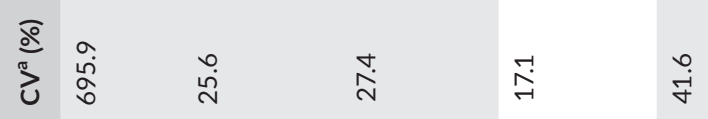

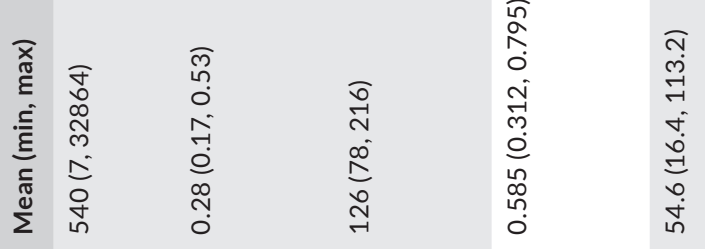

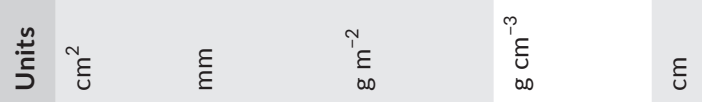

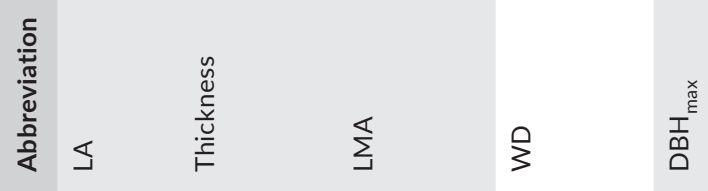

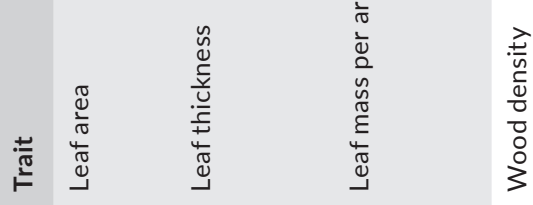

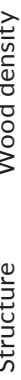

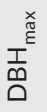

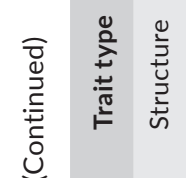

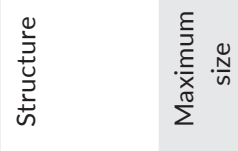

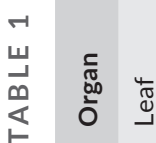

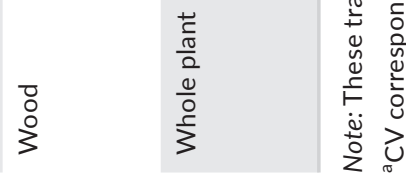




$$
R=\left(\begin{array}{cccc}
1 & \rho_{\alpha_{j}, \beta_{1 j}} & \rho_{\alpha_{j}, \beta_{\ldots j}} & \rho_{\alpha_{j}, \beta_{4 j}} \\
\rho_{\beta_{1 j}, \alpha_{j}} & 1 & \rho_{\beta_{1 j}, \beta \ldots j} & \rho_{\beta_{1 j}, \beta_{4 j}} \\
\vdots & \vdots & \vdots & \vdots \\
\rho_{\beta_{4 j}, \alpha_{j}} & \rho_{\beta_{4 j}, \beta_{1 j}} & \rho_{\beta_{4 j}, \beta_{\ldots j}} & 1
\end{array}\right) \quad \text { [Correlation matrix of species - level params. ], }
$$

$\gamma_{k} \sim \operatorname{Normal}\left(0, \sigma_{\gamma}\right) \quad$ [Adaptive priors for the $k$ plots],

$\delta_{t} \sim \operatorname{Normal}\left(0, \sigma_{\delta}\right) \quad$ [Adaptive priors for the $t$ time periods]

$\lambda_{i} \sim \operatorname{Normal}\left(0, \sigma_{\lambda}\right) \quad$ [Adaptive priors for the $i$ individuals],

$\alpha_{0}, \beta_{1-4,0} \sim \operatorname{Normal}(0,1) \quad$ [Priors for grand intercept and slopes],

$\sigma_{\alpha}, \sigma_{\beta_{1-4}}, \sigma_{\gamma}, \sigma_{\delta}, \sigma_{\lambda}, \sigma_{R} \sim \operatorname{HalfNormal}(0,1)$

[Priors for standard deviation params. ],

$$
R \sim L K J \operatorname{corr}(2) \quad \text { [Prior for correlation matrix], }
$$

where $\alpha_{j}$ characterizes the intrinsic AGR of species $j$ and $\beta_{1 j}, \beta_{2 j}, \beta_{3 j}$, and $\beta_{4 j}$ characterize the AGR response of species $j$ to tree size, mean climate (1981-2010), standardized climate anomalies, and plot basal area in plot $k$ for time interval $t$. The parameter $\alpha_{0}$ represents the grand intercept, and the parameters $\beta_{1-4,0}$ are the grand slopes of model covariates whose posterior distributions represent the effect of covariates on AGR across all species.

The matrix of fitted correlation coefficients among all pairs of species-level intercepts and slopes $\left(\alpha_{j}, \beta_{1 j}, \beta_{2 j}, \beta_{3 j}\right.$ and $\left.\beta_{4 j}\right)$ allows evaluating correlations among species intrinsic growth rate (intercepts $\alpha_{j}$ ) and species AGR sensitivity to model covariates $\left(\beta_{1-4 j}\right)$. For instance, if we consider VPD or MCWD, the $\rho_{\beta 2 \mathrm{j}, \beta 3 j}$ parameter will be used to address question 2, that is, whether species AGR sensitivity to long-term conditions (eg, of VPD) is correlated to AGR sensitivity to climate anomalies (of VPD). Similarly, a model with a negative $\rho_{\alpha \mathrm{j}, \beta 3 j}$ parameter and a negative $\beta_{3,0}$ slope would indicate that species with higher intrinsic growth rate $\left(\alpha_{j}\right)$ tend to have higher sensitivity (ie, more negative slopes) to climate anomalies (ie, the intrinsic growth-related part of question 3). Using covariance matrix to pull information across species-level intercepts and slopes through the multinormal distribution also improves the accuracy of posterior likelihood estimates both across and within species (hierarchical levels 1 and 2, respectively) while limiting risks of overfitting through adaptive regularizing priors, or partial pooling (McElreath, 2020).

Parameters $\gamma_{k}, \delta_{t}, \lambda_{i}$ are varying intercepts capturing the residual variation in expected individual AGR occurring among forest plots, time periods between consecutive censuses (characterized by the years beginning and ending a given census period) and individual stems, respectively. This model was run separately for each of the four climate variables ( $T_{\text {mean }}, S R A D, V P D$ and MCWD) to manage model complexity (representing a total of four M1 models).

\subsection{2 | M2: Trait-mediated species-level tree growth response to climate}

Models M2 have the same hierarchical structure as M1, but additionally include the role of species traits in AGR response to climate and only consider 75 locally dominant species with trait data instead of all 509 species. Models M2 were used to address question 3, that is, to test whether traits mediate climate effects on tree growth. We thus used a subset of 5191 individuals from the 75 species with trait data. In M2, the species-level intercept and slopes are modelled as depending on species mean trait value such that both speciesspecific intrinsic AGR and AGR sensitivity to covariates can be influenced (either accentuated or lessened) by species traits (Fortunel et al., 2018; Rüger et al., 2012; Uriarte et al., 2016) as:

$$
\begin{aligned}
& \log \left(\mathrm{AGR}_{i, j, k, t}\right) \sim \operatorname{Normal}\left(\mu_{i, j, k, t}, \sigma_{R}\right) \quad \text { [Likelihood] } \\
& \mu_{\mathrm{i}, \mathrm{j}, \mathrm{k}, \mathrm{t}}=\alpha_{\mathrm{j}}+\beta_{1 \mathrm{j}} \times \log \left(\mathrm{DBH}_{\mathrm{i}, t}\right)+\beta_{2 \mathrm{j}} \times \text { meanClim }_{k}+\beta_{3 j} \\
& \times \text { climAnom }{ }_{k, t}+\beta_{4 j} \times \mathrm{BA}_{k, t}+\gamma_{k}+\delta_{t}+\lambda_{i} \quad \text { [Linear model - level 1], } \\
& \alpha_{j}=\alpha_{0}+\alpha_{1} \times \log \left(\text { Trait }_{j}\right) \quad \text { [Linear model - level 2] }, \\
& \beta_{2-4 j}=\beta_{2-4,0}+\beta_{2-4,1} \times \log \left(\text { Trait }_{j}\right) \quad[\text { Linear model - level 2] }
\end{aligned}
$$

$$
\begin{aligned}
& \left(\begin{array}{c}
\alpha_{j} \\
\beta_{1 j} \\
\vdots \\
\beta_{4 j}
\end{array}\right) \sim \text { MVNormal }\left(\begin{array}{c}
\alpha_{0} \\
\beta_{1,0} \\
\vdots \\
\beta_{4,0}
\end{array}\right), S \quad \text { [Adaptive priors for species - level param.], } \\
& S=\left(\begin{array}{cccc}
\sigma_{\alpha} & 0 & 0 & 0 \\
0 & \sigma_{\beta_{1}} & 0 & 0 \\
\vdots & \vdots & \ddots & \vdots \\
0 & 0 & 0 & \sigma_{\beta_{4}}
\end{array}\right) R\left(\begin{array}{cccc}
\sigma_{\alpha} & 0 & 0 & 0 \\
0 & \sigma_{\beta_{1}} & 0 & 0 \\
\vdots & \vdots & \ddots & \vdots \\
0 & 0 & 0 & \sigma_{\beta_{4}}
\end{array}\right) \quad \text { [Construction of covariance matrix], }
\end{aligned}
$$




$$
R=\left(\begin{array}{cccc}
1 & \rho_{\alpha_{j}, \beta_{1 j}} & \rho_{\alpha_{j}, \beta_{\ldots j}} & \rho_{\alpha_{j}, \beta_{4 j}} \\
\rho_{\beta_{1 j}, \alpha_{j}} & 1 & \rho_{\beta_{1 j}, \beta \ldots j} & \rho_{\beta_{1 j}, \beta_{4 j}} \\
\vdots & \vdots & \vdots & \vdots \\
\rho_{\beta_{4 j}, \alpha_{j}} & \rho_{\beta_{4 j} ; \beta_{1 j}} & \rho_{\beta_{4 j} ; \beta_{1 j}} & 1
\end{array}\right) \quad \text { [Correlation matrix of species - level params.], }
$$

where Equations (4.1), (4.2), (4.5)-(4.7) are the same as Equations (3.1)-(3.5) of M1, whilst species-level intercepts and slopes are mediated by species mean trait value (Equations 4.3-4.4; see priors in Supplementary Methods S1). Parameter $\alpha_{1}$ is the species-level departure from the grand intercept $\left(\alpha_{0}\right)$ for an increase of one standard deviation in the $\log \left(\right.$ Trait $_{j}$ ) value of species $j$ (direct effect of trait on AGR), whilst $\beta_{2-4,1}$ are the departures from the grand slope of the corresponding model covariates for an increase of one standard deviation in the $\log$ (Trait. ) value of species $j$ (trait mediation of AGR response to climate and stand structure). If the sign of a trait coefficient $\left(\beta_{2-4,1}\right)$ is the same as that of the corresponding grand covariate effect $\left(\beta_{2-4,0}\right)$, then increasing values of the Trait ${ }_{j}$ accentuate the effect of the covariate (meanClim, climAnom or BA) on tree growth (ie, push $\beta_{3 j}$ further away from 0 ). If the signs are different, increasing values of Trait ${ }_{j}$ attenuate the effect of covariate $c$ (ie, pull $\beta_{c, j}$ closer to 0 ). We did not include the role of species traits in AGR response to tree size because some traits can change through tree ontogeny (Fortunel et al., 2020) and our trait data does not encompass species tree size ranges. M2 models were run separately for each of the four climate variables and for each of the 15 functional traits to manage model complexity (representing a total of $60 \mathrm{M} 2$ models).

In both M1 and M2 models, we standardized the response variable $\log (A G R)$ and all covariates-but climate anomalies-to mean zero and unit standard deviation, to allow relative importance comparisons between covariates through slope coefficients (Schielzeth, 2010), and to ease plausible weakly-informative prior assignment to the parameters (McElreath, 2020) (see Supplementary Methods S1). We did not standardize averaged monthly anomalies to maintain their interpretability as deviations from long-term means in terms of plot-specific units of standard deviation (see Equation 2; ie, mean anomaly covariate slope coefficients are not directly comparable to other covariate mean slopes). Individual trait measurements were averaged per species and log-transformed prior to standardization to mean zero and unit standard deviation, thus implying that parameter $\beta_{2-4, j}$ corresponds to $\beta_{2-4,0}$ at the mean trait value of the dataset.

\subsection{3 | M3: Plot-level tree growth response to} climate anomalies and interaction with mean climate

M3 models evaluate plot-level growth response to climate anomalies, and whether it varies depending on local mean climates (ie, question 4; e.g. whether plot-level AGR sensitivity to VPD anomalies is higher in drier sites). M3 models were run on the basis of all 509 species and did not include trait data, like M1 models. We focused on the tree growth at the plot level and modelled the expected $\log (A G R)$ as a linear function of mean climate and climate anomalies. We used a similar Bayesian hierarchical model as described for M2, where plotspecific average AGR depended on climate anomalies, whose effect on AGR itself depended on the plot mean climate, as:

$$
\log \left(A G R_{i, j, k, t}\right) \sim \operatorname{Normal}\left(\mu_{i, j, k, t}, \sigma_{R}\right) \quad \text { [Likelihood] }
$$

$\mu_{i, j, k, t}=\alpha_{k}+\beta_{1 k} \times$ climAnom $_{k, t}+\gamma_{j}+\delta_{t}+\lambda_{i} \quad[$ Linear model - level 1],

$$
\alpha_{k}=\alpha_{0}+\alpha_{1} \times \text { meanClim }_{k} \quad \text { [Linear model - level 2], }
$$

$$
\beta_{1 \mathrm{k}}=\beta_{1,0}+\beta_{1,1} \times \text { meanClim }_{k} \quad \text { [Linear model - level 2], }
$$

$\left(\begin{array}{c}\alpha_{k} \\ \beta_{1 k}\end{array}\right) \sim$ MVNormal $\left(\begin{array}{c}\alpha_{0} \\ \beta_{1,0}\end{array}\right)$ [Adaptive priors for plot - level params. ],

$S=\left(\begin{array}{cc}\sigma_{\alpha} & 0 \\ 0 & \sigma_{\beta_{1}}\end{array}\right) R\left(\begin{array}{cc}\sigma_{\alpha} & 0 \\ 0 & \sigma_{\beta_{1}}\end{array}\right) \quad$ [Construction of covariance matrix]

$R=\left(\begin{array}{cc}1 & \rho_{\alpha, \beta_{1}} \\ \rho_{\alpha, \beta_{1}} & 1\end{array}\right) \quad$ [Correlation matrix of plot - level params. ],

where $\alpha_{k}$ is the average growth rate in plot $k$, and $\beta_{1 k}$ characterises the growth response of plot $k$ to standardized climate anomalies for time interval t. $\alpha_{0}$ is the mean intercept value (ie, mean absolute growth rate) across plots, and $\alpha_{1}$ is the departure from the grand mean for one unit increase in mean climate (see d priors in Supplementary Methods S1). $\beta_{1,0}$ is the grand slope of climate anomalies, and $\beta_{1,1}$ is the departure from this grand mean for a one-unit increase in mean climate (mediation of the effect of anomalies on growth by the plot mean climate). Parameters $\gamma_{j}, \delta_{t}, \lambda_{i}$ are varying intercepts for species, census periods, and individual stems, respectively.

We run M3 models only for two climate variables (VPD and SRAD), as we found they were the most important climate variables for tree growth in M1 and M2 models (see Section 3). Standardization of variables was carried out as for M1.

\subsubsection{Trends in climate over time}

To explore the implications of the effects of climate anomalies on tree growth, we built a separate set of hierarchical Bayesian models to test for linear temporal trends in mean annual climate variables between 1971 and 2019. We used varying year slopes per plots to 
allow plot-specific trends (model details in Supplementary Methods S1). We also run the models for the period 2000 to 2019 for comparison with recent analyses suggesting an increasing rate of VPD increase over time since the late 90s (Yuan et al., 2019). Annual mean temperature and VPD increased by $0.015^{\circ} \mathrm{C}$ and $0.02 \mathrm{hPa}$ per year between 1971 and $2019\left(R^{2}=.97\right.$ and .84 , respectively, Table S4; illustration in Figure $1 \mathrm{~b}$ ) and by $0.038^{\circ} \mathrm{C}$ and $0.045 \mathrm{hPa}$ per year between 2000 and $2019\left(R^{2}=.98\right.$ and .81 , respectively, Table S4). There was no general temporal trend for MCWD or SRAD (Figure 1c).

\subsection{5 | Analysis of model outcomes}

All model parameter posteriors were summarized through their median and 95\%-highest posterior density interval (HPDI) (i.e. the narrowest posterior interval encompassing $95 \%$ of the probability mass, corresponding to the coefficient values most consistent with the data; McElreath, 2020). Model covariates were considered important at two high levels of confidence when their coefficient had a posterior probability of over $95 \%$ or $90 \%$ of being either positive or negative (HPDI not encompassing zero).

The goodness-of-fit of the models was assessed through the squared Pearson correlation between the observed AGR and the AGR predicted by the fitted model $\left(R^{2}\right)$. M1 and M2 models had high explanatory power, with $R^{2}$ of .46 and .52 on average, respectively. M3 models, with VPD and SRAD as climate variables, had an $R^{2}$ of .67 and .63 , respectively.

Bayesian updating of parameters was performed via the No-UTurn Sampler (NUTS) in Stan (Carpenter et al., 2017), using three chains and 3000 steps (1500 warm-up). All models mixed well and converged (Rhat within $<0.01$ of 1 ). Models were run in the $\mathrm{R}$ environment (R Core Team, 2020) using the packages 'brms' (Bürkner, 2017), 'tidybayes' (Kay, 2020) and 'tidyverse' (Wickham et al., 2019).

\section{3 | RESULTS}

\subsection{Contribution of climate means and anomalies to tree growth}

The M1 models of tree growth, based on all 509 tree species and not including trait data, indicated that the main climate drivers affecting tree growth across species were the climate means and anomalies in $T_{\text {mean }}$, SRAD and VPD (Figure 2; Figure S3, Table S5). Tree growth was higher in forests with higher mean $T_{\text {mean }}$, SRAD and VPD ( $\beta_{2 j}: 0.17$ [0.08, 0.26], 0.05 [0.02, 0.08], and 0.09 [0.02, 0.17], respectively; median and 95\%-HPDI; unless otherwise stated, all intervals are 95\%-HPDI). However, tree growth was reduced when forests experienced positive anomalies in temperature, SRAD and VPD $\left(\beta_{3 j}:-0.12[-0.17,-0.07],-0.34\right.$ [-0.42, $-0.26]$ and $-0.13[-0.19,-0.06]$, respectively). Contrary to our expectation, anomalies in MCWD had no clear effect on tree growth across species (Figure 2; Figure S2, Table S5). Tree growth sensitivity to climate, stand structure and tree size varied widely among species (illustration in Figure S3). Similar results were obtained from the M2 models (a subset of 75 species with trait data) (Figure S5a-d, Table S5), though we no longer detected the effects of temperature anomalies and VPD and solar radiation means in this reduced dataset.

\section{2 | Coordinated tree growth sensitivities to climate means and anomalies}

Using the fitted matrix of correlations among species-level intercepts and slopes from the M1 models on all 509 species (matrix $R$, see Equation 3.5) allowed testing for different sensitivities to climate anomalies between fast- and slow-growing species, and between species growing better at opposite extremes of the range

Effects of climate, stand structure and size on tree growth (509 species)

FIGURE 2 Grand effects of climate, stand structure and tree size on tree growth (based on all 509 species; four M1 models). Red and blue arrows indicate clear negative and positive effects (ie, slope coefficient 95\%-highest posterior density interval [HPDI] not encompassing zero). Arrow widths are proportional to the median of the covariate slope posteriors (grand slopes, values in rectangles; see $\beta_{1-4,0}$ in Equations 3.13.11) (details in Figure S2 and Table S5) Climate mean (1981-2010)

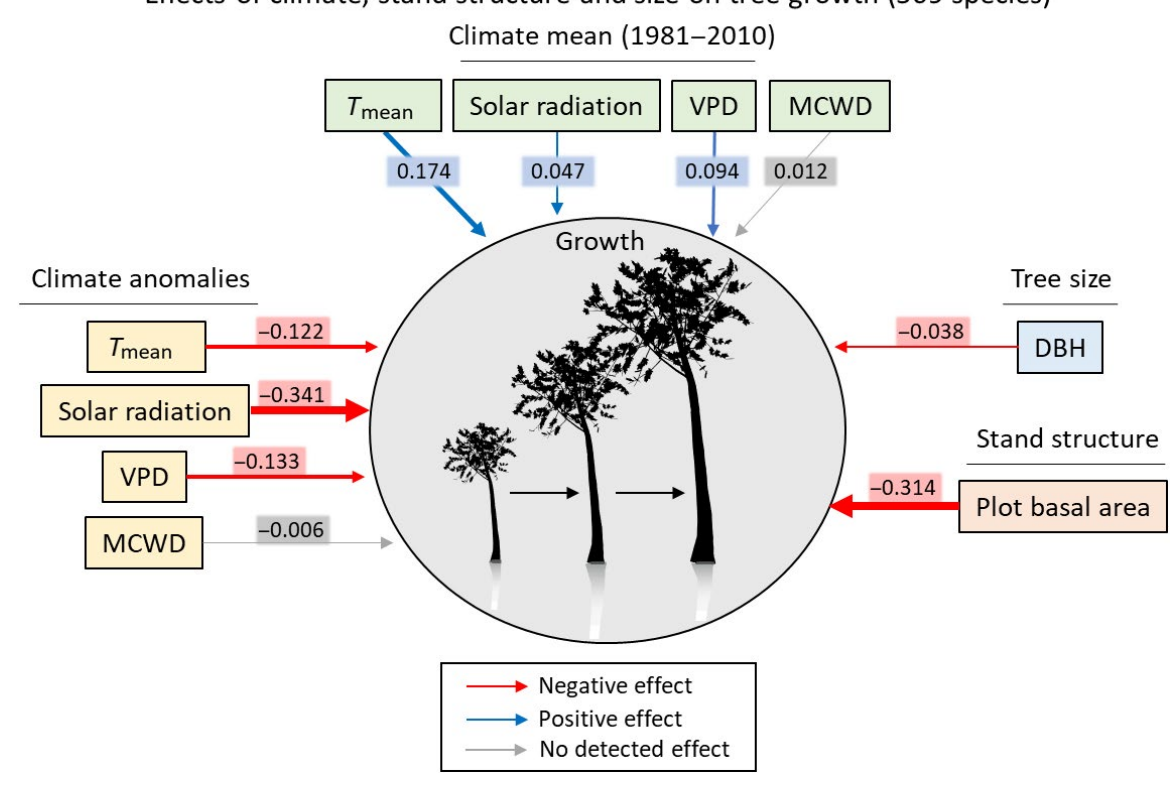


of mean climates. Fast-growing species (ie, with high intrinsic AGR) were more sensitive than slow-growing species to the negative effects of both VPD anomalies and plot basal area on tree growth (Figure 3c; Figure S4; $\rho=-0.36[-0.48,-0.23]$ and $\rho=-0.29[-0.41$, -0.17], respectively). Species that grew better in cloudier forests (ie, lower SRAD) tended to show steeper growth decreases when experiencing positive anomalies in solar radiation (Figure 3b; $\rho=$ $0.17,[0.01,0.33])$. Species that grew faster in drier forests (ie, higher VPD) were more negatively affected by positive VPD anomalies (Figure 3a; $\rho=-0.15[-0.29,0.00]$ ). Finally, species most negatively affected by positive anomalies in VPD also experienced stronger growth decrease in denser forests (high basal area) (Figure 3d; $\rho=$ $0.27[0.14,0.40])$.

\section{3 | Drier rainforests are more sensitive to VPD anomalies}

M3 models highlighted clear interactions between the effects of climate anomalies and mean climate for VPD $\left(\beta_{1,1}:-0.26[-0.39\right.$, -0.13]; see Equations (3.1)-(3.11)), and to a lesser extent for solar radiation ( $\beta_{1,1}:-0.09$ [-0.18, -0.01], 90\%-HPDI; Table S5). Drier tropical rainforests showed a steeper decrease in plotlevel growth in response to increasing positive VPD anomalies (Figure 4a; Table S5). Cloudier forests exhibited a stronger decrease in plot-level growth with increasing positive SRAD anomalies (Figure 4b; Table S5).

\subsection{Functional traits influence species intrinsic tree growth and their response to climate drivers}

Based on the M2 models of tree growth for the subset of 75 locally dominant species with trait data, species intrinsic growth increased with dark respiration rate $\left(R_{\mathrm{d}}\right), \mathrm{DBH}_{\text {max }}$, leaf $\mathrm{P}$ content, Asat, $V_{\text {cmax }}$, leaf $\delta^{13} \mathrm{C}$ and LMA. (Figure 5; Figures S5e; details in Table S5). Species traits also mediated the effects of climate and forest structure on tree growth, either by accentuating them (species with high values of the trait respond more strongly) or by attenuating them (species with low values of the trait are more sensitive) (Figure 5; details in Figure S6; Table S5). Leaf $\delta^{13} \mathrm{C}$ and $\mathrm{P}$ content exacerbated the negative effects of positive anomalies in SRAD on tree growth, whilst $A_{\text {max }}, g_{\text {max }}, g_{\text {sat }}$ and $J_{\max }$ attenuated them (Figure 5; Figure S6f, Table S5). The negative effects of anomalies in VPD on tree growth were exacerbated in species with high leaf $\delta^{13} \mathrm{C}, \mathrm{DBH}_{\text {max }}$, leaf $\mathrm{P}$, and LMA, further confirming that VPD anomalies had the most negative effects on fast-growing species (Figure $3 c$ ), but also those with low $g_{\text {max }}$ or leaf area (Figure 5; Figure S6g). Tree growth was less reduced by denser forest environments (high plot basal areas) in species with high wood density, low $R_{\mathrm{d}}$ and low leaf $\delta^{13} \mathrm{C}$ (Figure 5; Figure S6i-I). (a)

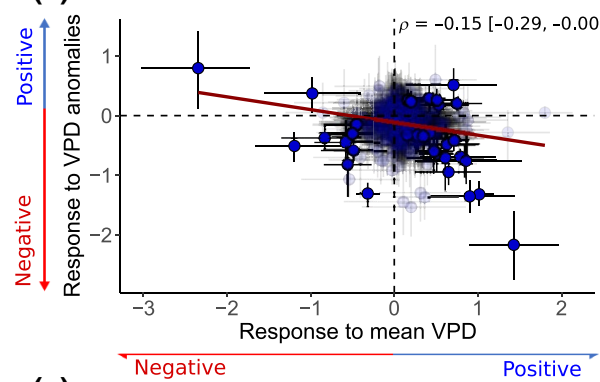

(c)

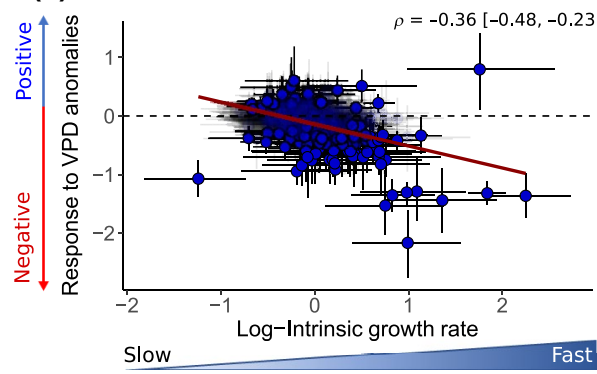

(b)

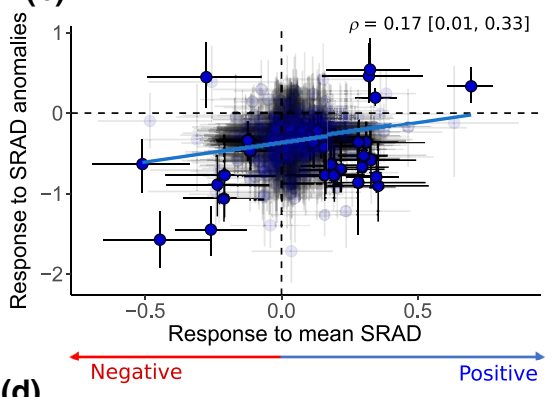

(d)

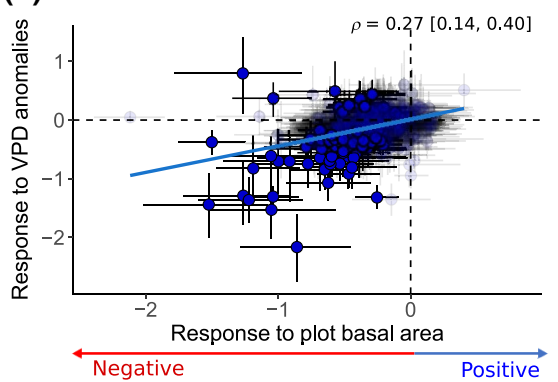

FIGURE 3 Correlations among species-level growth sensitivities highlighting joint responses to multiple drivers (M1 models; 509 species). Joint growth sensitivities to: (a) vapour pressure deficit (VPD) anomalies and mean VPD; (b) Solar radiation anomalies and mean solar radiation; (c) VPD anomalies and intrinsic growth rate; (d) VPD anomalies and plot basal area. Circles are species, placed at the median of their corresponding coefficient posteriors. Vertical and horizontal bars are 95\%-highest posterior density interval (HPDI) for the corresponding coefficients. Species for which both plotted coefficients were important are plain blue; other species are shaded. Blue and red regression lines indicate positive and negative correlations ( $\rho$, see Equation 3.5 in Supplementary Methods S1), respectively. Values beyond and below zero indicate positive and negative effects on growth rates, respectively. Mean, lower and upper 95\%-HPDI are in the upper right-hand corner of the figures 
Plot-level growth sensitivity to VPD and solar radiation anomalies across long-term means (1981-2010)

(a)

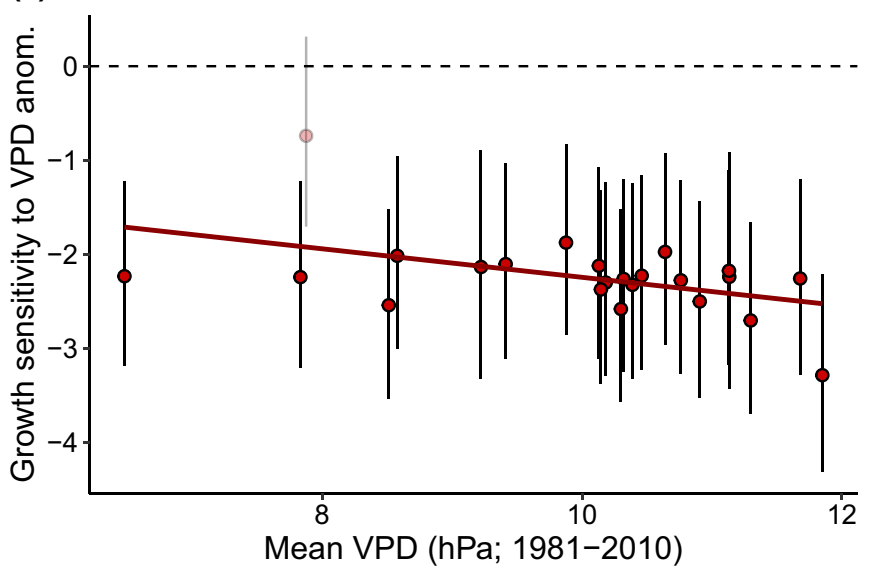

(b)

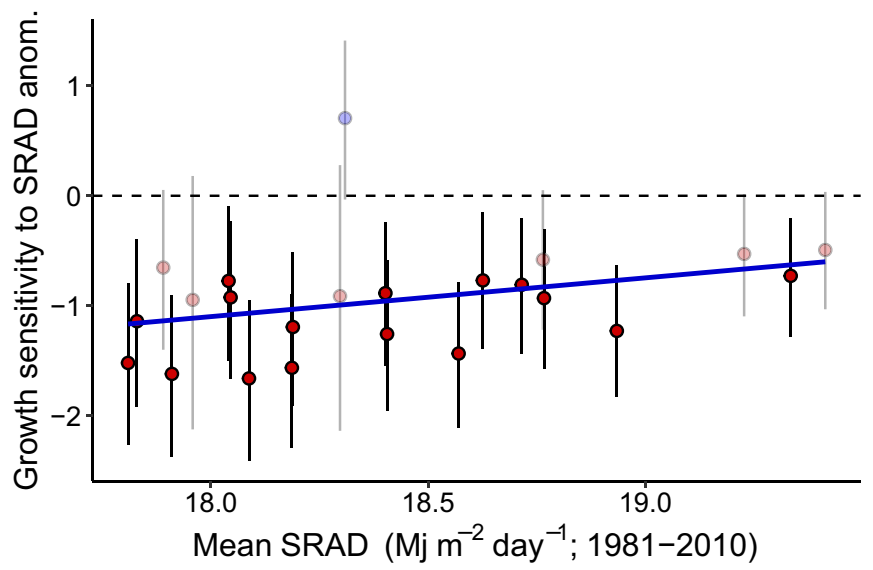

FIG URE 4 Plot-level growth sensitivity to positive (a) vapour pressure deficit (VPD) anomalies and (b) solar radiation (SRAD) anomalies (b) across the full range of the corresponding mean climate variable (M3 models). Circles and vertical bars are the median and 95\%-highest posterior density interval (HPDI) of the plot-level slope posteriors characterizing the growth rate responses to climate anomalies. The plotlevel models including VPD (a) and SRAD (b) had a marked interaction between anomalies and long-term mean (Table S5), so that plot-level sensitivities to a given anomaly depend on plots' long-term mean. (a, b) Illustrate those interactions through the differences of plot-level growth sensitivity to positive anomalies across the range of long-term means of the corresponding variable. The represented plot-level coefficients were calculated for a positive standardised anomaly equal to the 95th percentile of anomalies in the data, ie, a standardized anomaly of 0.8 (a) and 0.4 (b). The red and blue regression lines and shaded areas are decreasing and increasing slopes, respectively (median and 95\%-HPDI, not encompassing zero), of the represented plot-level coefficients along the long-term means. Horizontal dashed line: limit between positive and negative slope coefficients indicating a growth rate increase and decrease, respectively, with the positive anomaly

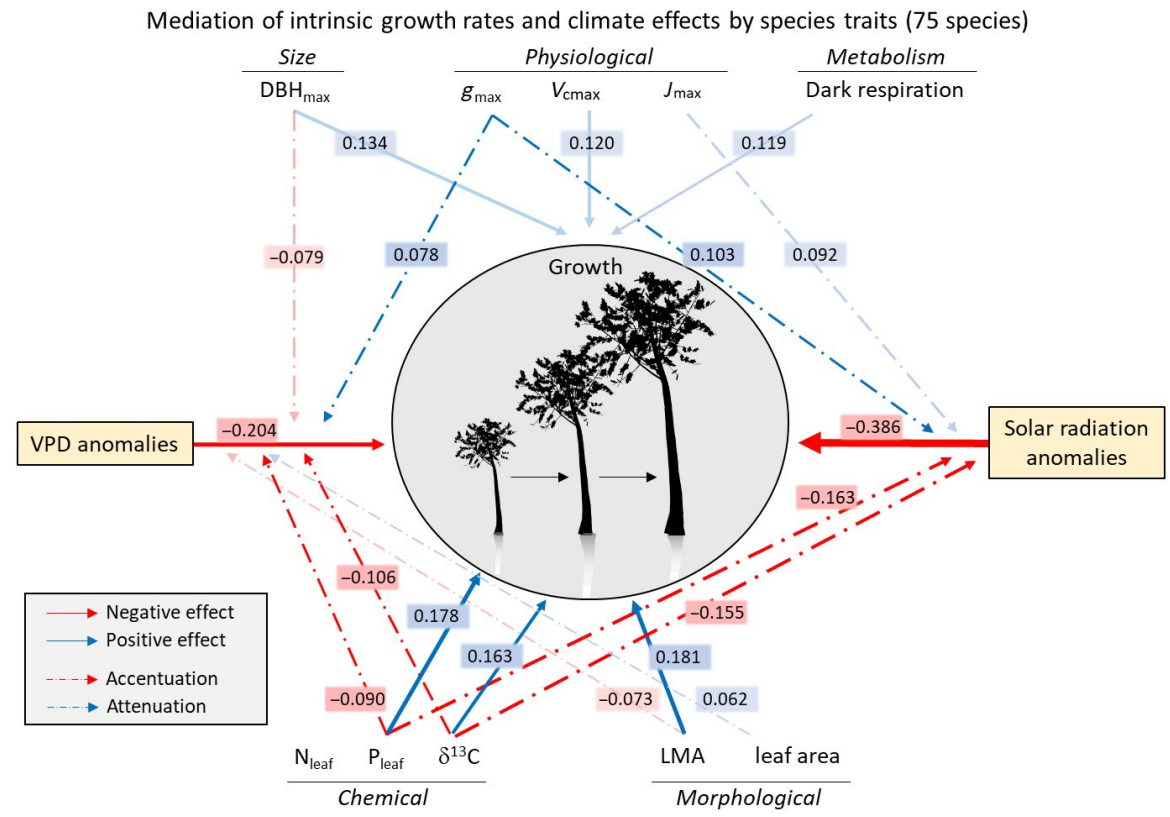

FIGURE 5 Mediation of intrinsic growth rate and climate anomaly effects on growth rate by species functional traits (M2 models; 75 species). The figure only presents important trait effects (95- or 90\%-highest posterior density interval [HPDI] not encompassing zero; non-transparent and semi-transparent arrows, respectively) (see Figures S5 and S6 for all model coefficients and all traits). Red and blue plain arrows indicate negative and positive direct effects of traits on species' intrinsic growth rate ( $\alpha_{1}$, see Equation 4.3). Dashed arrows are slope coefficients indicating indirect trait effects on growth through the effects of environmental covariates, ie, accentuation (red) or attenuation (blue) of the negative effects of VPD or SRAD anomalies when trait values increase ( $\beta_{3,1}$, see Equation 4.4). Arrow widths are proportional to the median of the covariate slope posterior across species (ie, grand slope; details in Figure S6 and Table S5) 


\section{4 | DISCUSSION}

In this study, we aimed to disentangle the influences of mean climate and climate anomalies on interannual tree growth and defined how species functional traits mediated climate effects by combining 49 years of demographic data, functional traits and climatic data along a climatic gradient in 23 tropical rainforests of Australia.

\subsection{What are the important climatic drivers for tree growth?}

Solar radiation (SRAD) and atmospheric water demand (VPD) anomalies were the two overarching climatic drivers of tree growth across pre-existing climatic conditions and species in our study. These two variables were also the main drivers of seasonal stand-level net primary productivity in aseasonal forests across the tropics (Rifai et al., 2018), and increasing VPD due to anthropogenic climate change has repeatedly been shown to impact tree growth, biomass and vegetation health (Eamus et al., 2013; Novick et al., 2016; Rifai et al., 2019; Sanginés de Cárcer et al., 2018; Yuan et al., 2019). The pervasive negative effect of VPD anomalies on tree growth in our study is consistent with expectations from stomatal conductance models (Grossiord et al., 2020), with stomatal closure and ensuing restriction of $\mathrm{CO}_{2}$ assimilation rate triggered by VPD values exceeding the climate mean and usual variation range. This negative effect of VPD is expected to be amplified by SRAD anomalies, as VPD depends on leaf temperature, which itself increases with SRAD (Grossiord et al., 2020). The negative influence of SRAD anomalies on tree growth may be additive to that of VPD anomalies, as previously shown (Krause \& Winter, 2020; Rifai et al., 2018, 2019). Furthermore, positive SRAD anomalies did not enhance tree growth but reduced it, as would be expected from a VPD-related effect. However, the effect of SRAD anomalies on tree growth was probably more than a mere reflection of VPD, as anomalies in SRAD and VPD were only moderately correlated ( $r=.33$, Table S3a). Excess or fluctuating light, and changes in light quantity and quality are other potential mechanisms underlying SRAD anomaly effects, as these can be direct physiological stressors (Krause \& Winter, 2020; Roeber et al., 2020), or indirectly influence the response to other abiotic or biotic stresses (Roeber et al., 2020).

The strong effect of VPD anomalies compared to the undetectable effect of MCWD anomalies suggests that VPD may limit tree growth before soil water becomes limiting, further confirming previous results in temperate and tropical forests (Choat et al., 2012; Konings et al., 2017; Novick et al., 2016; Rifai et al., 2018; Sanginés de Cárcer et al., 2018). This is a key result, given the generalized tree growth decrease potentially driven by increasing VPD anomalies, as VPD has been strongly increasing in the tropics due to anthropogenic climate change (Rifai et al., 2019). Yuan et al. (2019) highlighted a particularly-strong increasing VPD trend at the global scale beginning in the late 1990's (0.017 hPa/year). Modelling VPD anomalies through time from 2000 to 2019 in our dataset, we detected a 3.8-fold stronger VPD increase rate across all plots $(0.045 \mathrm{hPa} /$ year, 90\%-HPDI: 0.019, 0.066; $R^{2}=.80$; details in Table S4; eg Figure $1 \mathrm{~b}$ ). This trend itself was stronger than the 1971-2019 trend in our dataset $\left(0.020 \mathrm{hPa}\right.$ /year; $R^{2}=.84$; Table S4), indicating a sharperthan-previously-thought VPD increase in the past two decades. This rapid increase of VPD anomalies through time combined with the generalized ensuing decrease in tree growth and growth sensitivity variability to VPD among species (Figure S3, Table S5) suggests that tropical forest composition and functions may be strongly altered by ongoing climate change, especially by VPD. It is worth noting that soil water deficit also depends on evapotranspiration estimates accuracy and variables unaccounted for, here (eg, soil-water retention capacity, topography), so that the importance of soil-related water stresses should be interpreted with caution.

In spite of the suppressing effects of increasing anomalies in SRAD, VPD and Tmean, average growth rates were higher in warmer and sunnier forests (ie, higher long-term means), across species (Figure 2) and within many species (Table S5). While long-term $T_{\text {mean }}$ was highly correlated with elevation ( $r=-.95$; Table S3a), mean solar radiation was not correlated with neither elevation nor the other climate variables (Table S3a). This suggests that these forests are in general energy-limited along the elevation gradient (faster growth in lowland forests), and light-limited across the gradient, supporting previous results along an Amazon-Andes elevation gradient (Fyllas et al., 2017). Our gradient of mean climates encompassed 7 to $51 \%$ of the global-scale climate space of tropical forests, but did not encompass their driest and warmest conditions (see Figure S7). Future studies will need to cover a broader range of climate values to test how generalizable the relationships that we detected are for tropical forests worldwide.

\section{2 | Trade-offs in tree growth responses to climate}

We showed that two aspects allowed understanding the broad range of species differences in growth response to VPD anomalies: the long-term mean VPD where species grew better, and the contrast between slow- and fast-growing species (Figure 3a,c). The models including plot-specific responses to climate anomalies additionally showed that forest growth sensitivity to VPD anomalies was stronger in drier forests, mostly at the higher end of the VPD range (Figure 4a). This result could be driven by higher levels of obligate or facultative deciduousness, as even the wettest rainforests have seasonal peaks in leaf fall (Edwards et al., 2018) and the drier the forest the earlier the leaf fall peak and the shorter the growing season. Our results support recent findings indicating that drier forests could be more sensitive to increasing VPD anomalies (Aguirre-Gutiérrez et al., 2019, 2020; Esquivel-Muelbert et al., 2020; Powers et al., 2020), which would here translate into drier rainforests already being under water stress and therefore closer to a threshold of further growth 
decrease than moist rainforests. This effect may not be linear and will need to be further tested with more plots encompassing diverse water-stress conditions.

Similarly, Sullivan et al. (2020) recently argued that warmer forests may be closer to a temperature threshold beyond which woody productivity would decrease. In our study, this would translate into expectations that forests and species adapted to warmer conditions would respond more negatively to further temperature increases. Our results are consistent with this expectation but suggest that the temperature effect manifests itself indirectly through VPD.

Species that grew faster in cloudier forests showed the strongest growth reduction due to positive SRAD anomalies (Figure $3 b$ ). This may reflect species differences in light-use strategies, with species that grow well under low direct-sunlight conditions not benefitting from brighter conditions. This was supported by the stronger negative effects of SRAD anomalies in species with lower maximum photosynthetic capacity, stomatal conductance and electron transport capacity (Figure 5), a trait syndrome consistent with shade-tolerance strategies (He et al., 2019). This interpretation was supported in the plot-level analyses by the steeper growth rate decreases in the cloudier forests in response to positive SRAD anomalies (Figure 4b), which may stem from a plot-wide relatively more marked adaptation to shade tolerance.

\subsection{Functional traits mediate the effects of climate anomalies on tree growth}

Traits directly influenced species intrinsic growth rate in locally dominant species in our plot network. As expected, the intrinsic growth rate increased with metabolism $\left(R_{\mathrm{d}}\right)$, maximum size $\left(\mathrm{DBH}_{\max }\right)$ and acquisitive chemical and physiological traits related to the photosynthetic machinery (leaf $\mathrm{P}$ content, $A_{\text {sat }}$ and $V_{\text {cmax }}$ ). However, it also increased with leaf $\delta^{13} \mathrm{C}$ and LMA, contrary to expectations as high values of these traits correspond to tough, long-lived leaves and high intrinsic water use efficiency (Cernusak et al., 2013; Osnas et al., 2013). In our study, leaf $\delta^{13} \mathrm{C}$ was positively correlated with leaf $\mathrm{N}$ and $\mathrm{P}$ contents (Table $\mathrm{S} 3 \mathrm{~b}$ ), suggesting variation in $\delta^{13} \mathrm{C}$ among species may have been driven more by photosynthetic capacity than by stomatal conductance. The positive association of LMA and growth, also reported in previous studies (Gray et al., 2019; Poorter et al., 2008; Wills et al., 2018), could be explained by a change in the costbenefit balance of acquisitive traits with plant size (Gibert et al., 2016; Gray et al., 2019).

An overarching finding is that species traits can enhance our understanding of differences in species growth response to the anomalies of SRAD and VPD, and to forest stand structure. Our results confirmed that resource-acquisitive species overall had a higher intrinsic growth rates and that their growth was more sensitive to positive anomalies in SRAD and VPD. This highlights a trade-off between fast growth (via high allocation to acquisitive tissues) and sensitivity to atmospheric water stress, consistent with expectations from the 'fast-slow' plant economics spectrum (Reich, 2014).
Most physiological traits directly related to photosynthesis (Table 1) successfully captured species differences in growth sensitivity to SRAD anomalies (Figure 5; Figure S6), confirming the importance of physiological traits to investigate potential mechanisms underlying differences in demographic responses to climate change among species (Brodribb et al., 2020; Powers et al., 2020; Rowland et al., 2021). Increasing values of these traits attenuated the tree growth reduction following increasing SRAD anomalies (Figure 5; Figure S7), suggesting that species investing in a more responsive and flexible photosynthetic machinery may cope better with unusually high direct exposure to sunlight. Whilst most traits that increased species intrinsic growth rate also exacerbated the negative effects of VPD anomalies on tree growth, the mediation of SRAD anomalies by species traits was mostly independent of the fast-slow spectrum (Figure 5; Figures S5 and S6). For example, whilst leaf $\mathrm{P}$ concentration, stable carbon isotope ratio and the maximum photosynthetic capacity tended to increase intrinsic growth rate, the two former accentuated while the latter attenuated the negative effects of SRAD anomalies on tree growth (Figure 5).

Here, the data at hand did not allow us to integrate intraspecific or temporal trait variability into the growth models, nor could we consider traits from rare species that may occupy different parts of the trait space (Leitão et al., 2016; Mouillot et al., 2013; Violle et al., 2017). These sources of variation may potentially change some effect sizes (Bloomfield et al., 2018; Rowland et al., 2021; Yang et al., $2018,2021)$, although this would be unlikely to affect the direction of the effects shown here, as the structure of our multilevel models was centred on species ranking, which is usually conserved (Auger \& Shipley, 2013; Oliveras et al., 2020). Exploring sources of uncertainty in species traits such as a potential climate change-driven trait acclimation over time for certain traits (Bloomfield et al., 2018; Way \& Yamori, 2014), tissue-level traits not providing a consistent and generalizable upscaling to whole-tree energy allocations and strategies across species (Yang et al., 2018), or climate effects on growth being mediated by multivariate phenotypes (ie, trait interaction effects) (Laughlin et al., 2018; Pistón et al., 2019), will be a challenge to address in future studies, mostly in terms of data collection.

\subsection{Stand structure as a driver of tree growth variation}

Plot basal area consistently strongly reduced tree growth across species and explained more growth variation than mean climate for all four climate variables. Although plot basal area was partly correlated with elevation, the 30-year average of $T_{\text {mean }}$ and VPD $(r=.63,-.59$, and -.47 , respectively; Table S3a), the slope coefficient of the basal area remained virtually unchanged across models including $T_{\text {mean }}$, VPD, or the other less correlated covariates (and was much steeper than the slopes of long-term $T_{\text {mean }}$ or VPD), so that the stand structure effect detected here is unlikely to indirectly reflect $T_{\text {mean }}$ or VPD, and is likely to approximate-though in an imperfect spatially implicit way-the mean neighbourhood crowding of the plot. Furthermore, the faster 
growth in less dense environments across forest plots suggests a release from competition for light. This is supported by the general light-limitation suggested by the faster growth in sunnier sites. Slower growth in denser environments may also suggest an increase in competition for resources or attacks by natural enemies. Neighbourhood crowding has indeed been shown to strongly reduce tree growth in tropical and temperate forests (Clark et al., 2014; Fortunel et al., 2016; Uriarte et al., 2016; Zambrano et al., 2017). In line with these studies, we found that conservative species with high wood density suffered less growth reduction from increasing plot basal area, whilst acquisitive species with high dark respiration rate and leaf $\delta^{13} \mathrm{C}$ were more sensitive to increasing plot basal areas (Figures S5 and S6).

In summary, we have shown how long-term demographic data across multiple plots encompassing environmental gradients, combined with functional traits collection can yield insights into how climate affects the interannual variation of tree growth at different temporal scales, and give important clues into which species and forests may be particularly vulnerable to climate change, and why. Our findings emphasise the importance of functional traits-and notably those related to photosynthesis and water use efficiency-to understand species differences in demographic sensitivity to abiotic and biotic drivers. Future efforts to further characterise how climate and neighbourhood crowding affect tree growth, survival and population growth across environmental gradients, and how these effects are mediated by species traits will help improve predictions of forest response and future ecosystem functions to climate change under different trajectories.

\section{ACKNOWLEDGEMENTS}

We thank Alex Cheesman for his help with fieldwork in Bellenden Ker. DB was supported by the Philippe Wiener - Maurice Anspach Foundation (FWA) and the Belgian American Educational Foundation. GD was supported by the FWA. YM was supported by the Frank Jackson Foundation. The trait campaign and data analysis were funded by UK Natural Environmental Research Council (NERC) Grant NE/P001092/1 to YM, European Research Council projects T-FORCES (Tropical Forests in the Changing Earth System) to YM and OLP and GEM-TRAIT to YM. We are thankful to the Daintree Rainforest Observatory for providing a subsidy on accommodation and station fees, and thank the Australian Supersite Network, part of the Australian Government's Terrestrial Ecosystem Network (Daintree Rainforest, Cow Bay, and Robson Creek Supersites) for provision of data used as part of the study. Computational resources have been provided by the Consortium des Équipements de Calcul Intensif (CÉCI), funded by the Fonds de la Recherche Scientifique de Belgique (F.R.S.-FNRS) under Grant No. 2.5020.11 and by the Walloon Region.

\section{CONFLICT OF INTEREST}

The authors declare there are no competing interests.

\section{AUTHOR CONTRIBUTIONS}

David Bauman, Claire Fortunel and Yadvinder Malhi designed the study. David Bauman tidied and vetted the demographic and trait data and performed the analyses. David Bauman and Claire Fortunel designed the statistical models of tree growth. Sami W. Rifai helped generating the climatic covariates and created Figure 1a. Imma Oliveras and Jesús Aguirre-Gutiérrez contributed ideas and constructive feedback to early versions of the work. Jesús AguirreGutiérrez helped obtain climate data and provided feedback on an early version of the work. Lucas A. Cernusak and Lisa P. Bentley led the trait data collection, assisted by Raymond Dempsey, Brandon E. McNellis, Hugo R. Ninantay-Rivera, Jimmy R. Chambi Paucar and Paul E. Santos-Andrade. Michael F. Hutchinson provided the final raw climate data. Matt Bradford supplied demographic data for the 20 CSIRO plots and Robson Creek. Lucas A. Cernusak, Sami W. Rifai, Jesús Aguirre-Gutiérrez, Guillaume Delhaye provided feedback to part of the discussion. Susan G. W. Laurance contributed demographic data of Daintree Observatory. David Bauman led the writing with regular feedback from Yadvinder Malhi, Claire Fortunel and Sean M. McMahon on intermediate stages of the analyses and manuscript. All authors commented on the manuscript and gave their approval for publication.

\section{DATA AVAILABILITY STATEMENT}

The raw demographic data that supported the findings are available in Bradford et al. (2014; see References) and CSIRO Data Access Portal [https://doi.org/10.4225/08/59475c67be7a4]. The R code for the analyses of the study is in Supplementary Methods S2. The raw climate data and processed data used in the models are openly available in the Github repository at [https://github.com/davbauman/ Bauman_et_al_2021_GCB], and raw trait data will be available upon reasonable request.

\section{ORCID}

David Bauman (D) https://orcid.org/0000-0001-9115-6518 Claire Fortunel (D) https://orcid.org/0000-0002-8367-1605 Lucas A. Cernusak (iD) https://orcid.org/0000-0002-7575-5526 Lisa P. Bentley (D) https://orcid.org/0000-0002-6180-8842 Sean M. McMahon (D) https://orcid.org/0000-0001-8302-6908 Sami W. Rifai (D) https://orcid.org/0000-0003-3400-8601 Jesús Aguirre-Gutiérrez (D) https://orcid.org/0000-0001-9190-3229 Imma Oliveras (D) https://orcid.org/0000-0001-5345-2236 Matt Bradford (D) https://orcid.org/0000-0002-9925-0311 Susan G. W. Laurance (D) https://orcid.org/0000-0002-2831-2933 Guillaume Delhaye (D) https://orcid.org/0000-0003-3551-3730 Michael F. Hutchinson (D) https://orcid.org/0000-0001-8205-6689 Brandon E. McNellis (D) https://orcid.org/0000-0001-9604-8727 Paul E. Santos-Andrade (D) https://orcid.org/0000-0002-6635-0375 Oliver L. Phillips (D) https://orcid.org/0000-0002-8993-6168 Yadvinder Malhi (D) https://orcid.org/0000-0002-3503-4783

\section{REFERENCES}

Abatzoglou, J. T., Dobrowski, S. Z., Parks, S. A., \& Hegewisch, K. C. (2018). TerraClimate, a high-resolution global dataset of monthly climate and climatic water balance from 1958-2015. Scientific Data, 5,1-12. https://doi.org/10.1038/sdata.2017.191 
Aguirre-Gutiérrez, J., Malhi, Y., Lewis, S. L., Fauset, S., Adu-Bredu, S., Affum-Baffoe, K., Baker, T. R., Gvozdevaite, A., Hubau, W., Moore, S., Peprah, T., Ziemińska, K., Phillips, O. L., \& Oliveras, I. (2020). Long-term droughts may drive drier tropical forests towards increased functional, taxonomic and phylogenetic homogeneity. Nature Communications, 11, 1-10. https://doi.org/10.1038/s4146 7-020-16973-4

Aguirre-Gutiérrez, J., Oliveras, I., Rifai, S., Fauset, S., Adu-Bredu, S., Affum-Baffoe, K., Baker, T. R., Feldpausch, T. R., Gvozdevaite, A., Hubau, W., Kraft, N. J. B., Lewis, S. L., Moore, S., Niinemets, Ü., Peprah, T., Phillips, O. L., Ziemińska, K., Enquist, B., \& Malhi, Y. (2019). Drier tropical forests are susceptible to functional changes in response to a long-term drought. Ecology Letters, 22, 855-865. https://doi.org/10.1111/ele.13243

Aragão, L. E. O. C., Malhi, Y., Roman-Cuesta, R. M., Saatchi, S., Anderson, L. O., \& Shimabukuro, Y. E. (2007). Spatial patterns and fire response of recent Amazonian droughts. Geophysical Research Letters, 34, L07701. https://doi.org/10.1029/2006GL028946

Atkin, O. K., Bloomfield, K. J., Reich, P. B., Tjoelker, M. G., Asner, G. P., Bonal, D., Bönisch, G., Bradford, M. G., Cernusak, L. A., Cosio, E. G., Creek, D., Crous, K. Y., Domingues, T. F., Dukes, J. S., Egerton, J. J. G., Evans, J. R., Farquhar, G. D., Fyllas, N. M., Gauthier, P. P. G., ... Zaragoza-Castells, J. (2015). Global variability in leaf respiration in relation to climate, plant functional types and leaf traits. New Phytologist, 206, 614-636. https://doi.org/10.1111/nph.13253

Auger, S., \& Shipley, B. (2013). Inter-specific and intra-specific trait variation along short environmental gradients in an old-growth temperate forest. Journal of Vegetation Science, 24, 419-428. https://doi. org/10.1111/j.1654-1103.2012.01473.x

Bennett, A. C., Dargie, G. C., Cuni-Sanchez, A., Tshibamba Mukendi, J., Hubau, W., Mukinzi, J. M., Phillips, O. L., Malhi, Y., Sullivan, M. J. P., Cooper, D. L. M., Adu-Bredu, S., Affum-Baffoe, K., Amani, C. A., Banin, L. F., Beeckman, H., Begne, S. K., Bocko, Y. E., Boeckx, P., Bogaert, J., ... Lewis, S. L. (2021). Resistance of African tropical forests to an extreme climate anomaly. Proceedings of the National Academy of Sciences United States of America, 118, e2003169118. https://doi.org/10.1073/pnas.2003169118

Bloomfield, K. J., Cernusak, L. A., Eamus, D., Ellsworth, D. S., Colin Prentice, I., Wright, I. J., Boer, M. M., Bradford, M. G., Cale, P., Cleverly, J., Egerton, J. J. G., Evans, B. J., Hayes, L. S., Hutchinson, M. F., Liddell, M. J., Macfarlane, C., Meyer, W. S., Prober, S. M., Togashi, H. F., ... Atkin, O. K. (2018). A continental-scale assessment of variability in leaf traits: Within species, across sites and between seasons. Functional Ecology, 32, 1492-1506. https://doi. org/10.1111/1365-2435.13097

Bradford, M. G., Murphy, H. T., Ford, A. J., Hogan, D. L., \& Metcalfe, D. J. (2014). Long-term stem inventory data from tropical rain forest plots in Australia. Ecology, 95, 2362-3000. https://doi. org/10.1890/14-0458R.1

Brienen, R. J., Schöngart, J., \& Zuidema, P. A. (2016). Tree rings in the tropics: Insights into the ecology and climate sensitivity of tropical trees. In G. Goldstein, \& L. S. Santiago (Eds.), Tropical tree physiology - adaptations and responses in a changing environment (pp. 439-461). Springer.

Brodribb, T. J., Powers, J., Cochard, H., \& Choat, B. (2020). Hanging by a thread? Forests and drought. Science, 368, 261-266. https://doi. org/10.1126/science.aat7631

Bürkner, P.-C. (2017). brms: An R package for Bayesian multilevel models using Stan. Journal of Statistical Software, 80, 1-28.

Carpenter, B., Gelman, A., Hoffman, M. D., Lee, D., Goodrich, B., Betancourt, M., Brubaker, M., Guo, J., Li, P., \& Riddell, A. (2017) Stan: A probabilistic programming language. Journal of Statistical Software, 76, 1-32.

Cernusak, L. A., Ubierna, N., Winter, K., Holtum, J. A. M., Marshall, J. D., \& Farquhar, G. D. (2013). Environmental and physiological determinants of carbon isotope discrimination in terrestrial plants. New Phytologist, 200, 950-965. https://doi.org/10.1111/ nph.12423

Chave, J., Coomes, D., Jansen, S., Lewis, S. L., Swenson, N. G., \& Zanne, A. E. (2009). Towards a worldwide wood economics spectrum. Ecology Letters, 12, 351-366. https://doi. org/10.1111/j.1461-0248.2009.01285.x

Choat, B., Jansen, S., Brodribb, T. J., Cochard, H., Delzon, S., Bhaskar, R., Bucci, S. J., Feild, T. S., Gleason, S. M., Hacke, U. G., Jacobsen, A. L., Lens, F., Maherali, H., Martínez-Vilalta, J., Mayr, S., Mencuccini, M., Mitchell, P. J., Nardini, A., Pittermann, J., ... Zanne, A. E. (2012). Global convergence in the vulnerability of forests to drought. Nature, 491, 752-755. https://doi.org/10.1038/nature11688

Clark, J. S. (2003). Uncertainty and variability in demography and population growth: A hierarchical approach. Ecology, 84, 1370-1381. https://doi.org/10.1890/0012-9658(2003)084[1370:UAVID A]2.0.CO;2.

Clark, J. S., Bell, D. M., Kwit, M. C., \& Zhu, K. (2014). Competitioninteraction landscapes for the joint response of forests to climate change. Global Change Biology, 20, 1979-1991. https://doi. org/10.1111/gcb.12425

Condit, R., Aguilar, S., Hernandez, A., Perez, R., Lao, S., Angehr, G., Hubbell, S. P., \& Foster, R. B. (2004). Tropical forest dynamics across a rainfall gradient and the impact of an El Niño dry season. Journal of Tropical Ecology, 20, 51-72. https://doi.org/10.1017/S026646740 3001081

Coomes, D. A., Flores, O., Holdaway, R., Jucker, T., Lines, E. R., \& Vanderwel, M. C. (2014). Wood production response to climate change will depend critically on forest composition and structure. Global Change Biology, 20, 3632-3645. https://doi.org/10.1111/ gcb.12622

De Kauwe, M. G., Lin, Y.-S., Wright, I. J., Medlyn, B. E., Crous, K. Y., Ellsworth, D. S., Maire, V., Prentice, I. C., Atkin, O. K., Rogers, A., Niinemets, Ü., Serbin, S. P., Meir, P., Uddling, J., Togashi, H. F., Tarvainen, L., Weerasinghe, L. K., Evans, B. J., Ishida, F. Y., \& Domingues, T. F. (2016). A test of the 'one-point method' for estimating maximum carboxylation capacity from field-measured, light-saturated photosynthesis. New Phytologist, 210, 1130-1144. https://doi.org/10.1111/nph.13815

DeSoto, L., Cailleret, M., Sterck, F., Jansen, S., Kramer, K., Robert, E. M. R., Aakala, T., Amoroso, M. M., Bigler, C., Camarero, J. J., Čufar, K., Gea-Izquierdo, G., Gillner, S., Haavik, L. J., Hereş, A.-M., Kane, J. M., Kharuk, V. I., Kitzberger, T., Klein, T., ... Martínez-Vilalta, J. (2020). Low growth resilience to drought is related to future mortality risk in trees. Nature Communications, 11, 1-9. https://doi.org/10.1038/ s41467-020-14300-5

Eamus, D., Boulain, N., Cleverly, J., \& Breshears, D. D. (2013). Global change-type drought-induced tree mortality: Vapor pressure deficit is more important than temperature per se in causing decline in tree health. Ecology and Evolution, 3, 2711-2729. https://doi. org/10.1002/ece3.664

Edwards, W., Liddell, M. J., Franks, P., Nichols, C., \& Laurance, S. G. W. (2018). Seasonal patterns in rainforest litterfall: Detecting endogenous and environmental influences from long-term sampling. Austral Ecology, 43, 225-235. https://doi.org/10.1111/aec.12559.

Esquivel-Muelbert, A., Phillips, O. L., Brienen, R. J. W., Fauset, S., Sullivan, M. J. P., Baker, T. R., Chao, K.-J., Feldpausch, T. R., Gloor, E., Higuchi, N., Houwing-Duistermaat, J., Lloyd, J., Liu, H., Malhi, Y., Marimon, B., Marimon Junior, B. H., Monteagudo-Mendoza, A., Poorter, L., Silveira, M., ... Galbraith, D. (2020). Tree mode of death and mortality risk factors across Amazon forests. Nature Communications, 11(1). https://doi.org/10.1038/s41467-020-18996-3

Fortunel, C., Lasky, J. R., Uriarte, M., Valencia, R., Wright, S. J., Garwood, N. C., \& Kraft, N. J. B. (2018). Topography and neighborhood crowding can interact to shape species growth and distribution in a diverse Amazonian forest. Ecology, 99, 2272-2283. https://doi. org/10.1002/ecy.2441 
Fortunel, C., Stahl, C., Heuret, P., Nicolini, E., \& Baraloto, C. (2020). Disentangling the effects of environment and ontogeny on tree functional dimensions for congeneric species in tropical forests. New Phytologist, 226, 385-395. https://doi.org/10.1111/nph.16393

Fortunel, C., Valencia, R., Wright, S. J., Garwood, N. C., \& Kraft, N. J. B. (2016). Functional trait differences influence neighbourhood interactions in a hyperdiverse Amazonian forest. Ecology Letters, 19, 1062-1070. https://doi.org/10.1111/ele.12642

Fyllas, N. M., Bentley, L. P., Shenkin, A., Asner, G. P., Atkin, O. K., Díaz, S., Enquist, B. J., Farfan-Rios, W., Gloor, E., Guerrieri, R., Huasco, W. H., Ishida, Y., Martin, R. E., Meir, P., Phillips, O., Salinas, N., Silman, M., Weerasinghe, L. K., Zaragoza-Castells, J., \& Malhi, Y. (2017). Solar radiation and functional traits explain the decline of forest primary productivity along a tropical elevation gradient. Ecology Letters, 20, 730-740. https://doi.org/10.1111/ele.12771

Gibert, A., Gray, E. F., Westoby, M., Wright, I. J., \& Falster, D. S. (2016). On the link between functional traits and growth rate: Meta-analysis shows effects change with plant size, as predicted. Journal of Ecology, 104, 1488-1503. https://doi.org/10.1111/1365-2745.12594

Gray, E. F., Wright, I. J., Falster, D. S., Eller, A. S. D., Lehmann, C. E. R., Bradford, M. G., \& Cernusak, L. A. (2019). Leaf:wood allometry and functional traits together explain substantial growth rate variation in rainforest trees. AoB Plants, 11, 1-11. https://doi.org/10.1093/ aobpla/plzO24

Green, J. K., Seneviratne, S. I., Berg, A. M., Findell, K. L., Hagemann, S., Lawrence, D. M., \& Gentine, P. (2019). Large influence of soil moisture on long-term terrestrial carbon uptake. Nature, 565, 476-479. https://doi.org/10.1038/s41586-018-0848-x

Grossiord, C., Buckley, T. N., Cernusak, L. A., Novick, K. A., Poulter, B., Siegwolf, R. T. W., Sperry, J. S., \& McDowell, N. G. (2020). Plant responses to rising vapor pressure deficit. New Phytologist, 226, 1550-1566. https://doi.org/10.1111/nph.16485

Harris, R. M. B., Beaumont, L. J., Vance, T. R., Tozer, C. R., Remenyi, T. A., Perkins-Kirkpatrick, S. E., Mitchell, P. J., Nicotra, A. B., McGregor, S. Andrew, N. R., Letnic, M., Kearney, M. R., Wernberg, T., Hutley, L. B., Chambers, L. E., Fletcher, M.-S., Keatley, M. R., Woodward, C. A., Williamson, G., ... Bowman, D. M. J. S. (2018). Biological responses to the press and pulse of climate trends and extreme events. Nature Climate Change, 8, 579-587. https://doi.org/10.1038/s4155 8-018-0187-9

He, P., Wright, I. J., Zhu, S., Onoda, Y., Liu, H., Li, R., Liu, X., Hua, L., Oyanoghafo, O. O., \& Ye, Q. (2019). Leaf mechanical strength and photosynthetic capacity vary independently across 57 subtropical forest species with contrasting light requirements. New Phytologist, 223, 607-618. https://doi.org/10.1111/nph.15803

Hutchinson, M. F., Kesteven, J. L., \& Xu, T. (2014). Making the most of the ground based meteorological network using anomaly-based interpolation. In Proceedings session 5 of the Australian energy and water exchange initiative OzEWEX 2014. Canberra.

Hutchinson, M. F., \& Xu, T. (2013). ANUSPLIN version 4.4. Fenner School of Environment and Society, Australian National University.

Jentsch, A., Kreyling, J., \& Beierkuhnlein, C. (2007). A new generation of climate change experiments: Events, not trends. Frontiers in Ecology and the Environment, 5, 365-374. https://doi.org/10.1890/15409295(2007)5[365:ANGOCE]2.0.CO;2

Kay, M. (2020). tidybayes: Tidy data and geoms for Bayesian models. R package version 2.1.1. https//mjskay.github.io/tidybayes/. https:// doi.org/10.5281/zenodo.1308151

Konings, A. G., Williams, A. P., \& Gentine, P. (2017). Sensitivity of grassland productivity to aridity controlled by stomatal and xylem regulation. Nature Geoscience, 10, 284-288. https://doi.org/10.1038/ ngeo2903

Krause, G. H., \& Winter, K. (2020). The photosynthetic system in tropical plants under high irradiance and temperature stress. Progress in Botany, 82, 131-169.
Laughlin, D. C., Gremer, J. R., Adler, P. B., Mitchell, R. M., \& Moore, M. M. (2020). The net effect of functional traits on fitness. Trends in Ecology \& Evolution, 1-11. https://doi.org/10.1016/j. tree.2020.07.010

Laughlin, D. C., Strahan, R. T., Adler, P. B., \& Moore, M. M. (2018). Survival rates indicate that correlations between community-weighted mean traits and environments can be unreliable estimates of the adaptive value of traits. Ecology Letters, 21, 411-421. https://doi. org/10.1111/ele.12914

Leitão, R. P., Zuanon, J., Villéger, S., Williams, S. E., Baraloto, C., Fortunel, C., Mendonça, F. P., \& Mouillot, D. (2016). Rare species contribute disproportionately to the functional structure of species assemblages. Proceedings of the Royal Society B: Biological Sciences, 283(1828), 20160084. https://doi.org/10.1098/rspb.2016.0084

Liu, Z., Wu, C., \& Wang, S. (2017). Predicting forest evapotranspiration by coupling carbon and water cycling based on a critical stomatal conductance model. IEEE Journal of Selected Topics in Applied Earth Observations and Remote Sensing, 10, 4469-4477. https://doi. org/10.1109/JSTARS.2017.2715077

Malhi, Y., Aragao, L. E. O. C., Galbraith, D., Huntingford, C., Fisher, R., Zelazowski, P., Sitch, S., McSweeney, C., \& Meir, P. (2009). Exploring the likelihood and mechanism of a climate-change-induced dieback of the Amazon rainforest. Proceedings of the National Academy of Sciences United States of America, 106, 20610-20615. https://doi. org/10.1073/pnas.0804619106

Malhi, Y., Doughty, C. E., Goldsmith, G. R., Metcalfe, D. B., Girardin, C. A. J., Marthews, T. R., del Aguila-Pasquel, J., Aragão, L. E. O. C., Araujo-Murakami, A., Brando, P., da Costa, A. C. L., Silva-Espejo, J. E., Farfán Amézquita, F., Galbraith, D. R., Quesada, C. A., Rocha, W., Salinas-Revilla, N., Silvério, D., Meir, P., \& Phillips, O. L. (2015). The linkages between photosynthesis, productivity, growth and biomass in lowland Amazonian forests. Global Change Biology, 21 2283-2295. https://doi.org/10.1111/gcb.12859

McElreath, R. (2020). Statistical rethinking: A Bayesian course with examples in R and Stan. CRC Press.

McGill, B. J., Enquist, B. J., Weiher, E., \& Westoby, M. (2006). Rebuilding community ecology from functional traits. Trends in Ecology \& Evolution, 21,178-185. https://doi.org/10.1016/j.tree.2006.02.002

Mendivelso, H. A., Camarero, J. J., Gutiérrez, E., \& Zuidema, P. A. (2014). Time-dependent effects of climate and drought on tree growth in a Neotropical dry forest: Short-term tolerance vs. long-term sensitivity. Agricultural \& Forest Meteorology, 188, 13-23. https://doi. org/10.1016/j.agrformet.2013.12.010

Mouillot, D., Bellwood, D. R., Baraloto, C., Chave, J., Galzin, R., HarmelinVivien, M., Kulbicki, M., Lavergne, S., Lavorel, S., Mouquet, N., Paine, C. E. T., Renaud, J., \& Thuiller, W. (2013). Rare species support vulnerable functions in high-diversity ecosystems. PLoS Biology, 11, e1001569. https://doi.org/10.1371/journal.pbio.1001569

Muledi, J., Bauman, D., Jacobs, A., Meerts, P., Shutcha, M., \& Drouet, T. (2020). Tree growth, recruitment, and survival in a tropical dry woodland: The importance of soil and functional identity of the neighbourhood. Forest Ecology and Management, 460, 117894. https://doi.org/10.1016/j.foreco.2020.117894

Murphy, H. T., Bradford, M. G., Dalongeville, A., Ford, A. J., \& Metcalfe, D. J. (2013). No evidence for long-term increases in biomass and stem density in the tropical rain forests of Australia. Journal of Ecology, 101, 1589-1597. https://doi.org/10.1111/1365-2745.12163

Needham, J., Merow, C., Chang-Yang, C.-H., Caswell, H., \& McMahon, S. (2018). Inferring forest fate from demographic data: From vital rates to population dynamic models. Proceedings of the Royal Society B, 285, 20172050. https://doi.org/10.1098/rspb.2017.2050

Novick, K. A., Ficklin, D. L., Stoy, P. C., Williams, C. A., Bohrer, G., Oishi, A. C., Papuga, S. A., Blanken, P. D., Noormets, A., Sulman, B. N., Scott, R. L., Wang, L., \& Phillips, R. P. (2016). The increasing importance of atmospheric demand for ecosystem water and carbon fluxes. 
Nature Climate Change, 6, 1023-1027. https://doi.org/10.1038/ nclimate3114

Oliveras, I., Bentley, L., Fyllas, N. M., Gvozdevaite, A., Shenkin, A. F., Peprah, T., Morandi, P., Peixoto, K. S., Boakye, M., Adu-Bredu, S., Schwantes Marimon, B., Marimon Junior, B. H., Salinas, N., Martin, R., Asner, G., Díaz, S., Enquist, B. J., \& Malhi, Y. (2020). The influence of taxonomy and environment on leaf trait variation along tropical abiotic gradients. Frontiers in Forests and Global Change, 3, 1-14. https://doi.org/10.3389/ffgc.2020.00018

Osnas, J. L. D., Lichstein, J. W., Reich, P. B., \& Pacala, S. W. (2013). Global leaf trait relationships: Mass, area, and the leaf economics spectrum. Science, 340, 741-744. https://doi.org/10.1126/science.1231574

Pan, Y., Birdsey, R. A., Fang, J., Houghton, R., Kauppi, P. E., Kurz, W. A., Phillips, O. L., Shvidenko, A., Lewis, S. L., Canadell, J. G., Ciais, P., Jackson, R. B., Pacala, S. W., McGuire, A. D., Piao, S., Rautiainen, A., Sitch, S., \& Hayes, D. (2011). A large and persistent carbon sink in the world's forests. Science, 333(6045), 988-993.

Peters, J. M. R., López, R., Nolf, M., Hutley, L. B., Wardlaw, T., Cernusak, L. A., \& Choat, B. (2021). Living on the edge: A continental-scale assessment of forest vulnerability to drought. . Global Change Biology, 27, 3620-3641. https://doi.org/10.1111/gcb.15641

Pistón, N., Bello, F., Dias, A. T. C., Götzenberger, L., Rosado, B. H. P., Mattos, E. A., Salguero-Gómez, R., \& Carmona, C. P. (2019). Multidimensional ecological analyses demonstrate how interactions between functional traits shape fitness and life history strategies. Journal of Ecology, 2317-2328. https://doi. org/10.1111/1365-2745.13190

Poorter, L., Wright, S. J., Paz, H., Ackerly, D. D., Condit, R., IbarraManríquez, G., Harms, K. E., Licona, J. C., Martínez-Ramos, M., Mazer, S. J., Muller-Landau, H. C., Peña-Claros, M., Webb, C. O., \& Wright, I. J. (2008). Are functional traits good predictors of demographic rates? Evidence from five neotropical forests. Ecology, 89, 1908-1920. https://doi.org/10.1890/07-0207.1

Powers, J. S., Vargas G., G., Brodribb, T. J., Schwartz, N. B., PérezAviles, D., Smith-Martin, C. M., Becknell, J. M., Aureli, F., Blanco, R., Calderón-Morales, E., Calvo-Alvarado, J. C., Calvo-Obando, A. J., Chavarría, M. M., Carvajal-Vanegas, D., Jiménez-Rodríguez, C. D., Murillo Chacon, E., Schaffner, C. M., Werden, L. K., Xu, X., \& Medvigy, D. (2020). A catastrophic tropical drought kills hydraulically vulnerable tree species. Global Change Biology, 26, 3122-3133. https://doi.org/10.1111/gcb.15037

Quebbeman, J. A., \& Ramirez, J. A. (2016). Optimal allocation of leaflevel nitrogen: Implications for covariation of Vcmax and Jmax and photosynthetic downregulation. Journal of Geophysical Research: Biogeosciences, 121, 2464-2475.

R Core Team. (2020). R: A language and environment for statistical computing. R Foundation for Statistical Computing.

Reich, P. B. (2014). The world-wide 'fast-slow' plant economics spectrum: A traits manifesto. Journal of Ecology, 102, 275-301. https:// doi.org/10.1111/1365-2745.12211

Rifai, S. W., Girardin, C. A. J., Berenguer, E., del Aguila-Pasquel, J., Dahlsjö, C. A. L., Doughty, C. E., Jeffery, K. J., Moore, S., Oliveras, I., Riutta, T., Rowland, L. M., Murakami, A. A., Addo-Danso, S. D., Brando, P., Burton, C., Ondo, F. E., Duah-Gyamfi, A., Amézquita, F. F., Freitag, R., ... Malhi, Y. (2018). ENSO drives interannual variation of forest woody growth across the tropics. Philosophical Transactions of the Royal Society B: Biological Sciences, 373(1760), 20170410. https:// doi.org/10.1098/rstb.2017.0410

Rifai, S. W., Li, S., \& Malhi, Y. (2019). Coupling of El Niño events and longterm warming leads to pervasive climate extremes in the terrestrial tropics. Environmental Research Letters, 14(10), 105002. https://doi. org/10.1088/1748-9326/ab402f

Roeber, V. M., Bajaj, I., Rohde, M., Schmülling, T., \& Cortleven, A. (2020). Light acts as a stressor and influences abiotic and biotic stress responses in plants. Plant, Cell and Environment, 44, 645-664.
Rohner, B., Waldner, P., Lischke, H., Ferretti, M., \& Thürig, E. (2018). Predicting individual-tree growth of central European tree species as a function of site, stand, management, nutrient, and climate effects. European Journal of Forest Research, 137, 29-44. https://doi. org/10.1007/s10342-017-1087-7

Rowland, L., Oliveira, R. S., Bittencourt, P. R. L., Giles, A. L., Coughlin, I., Costa, P. D. B., Domingues, T., Ferreira, L. V., Vasconcelos, S. S., Junior, J. A. S., Oliveira, A. A. R., Costa, A. C. L., Meir, P., \& Mencuccini, M. (2021). Plant traits controlling growth change in response to a drier climate. New Phytologist, 229, 1363-1374. https:// doi.org/10.1111/nph.16972

Rüger, N., Wirth, C., Wright, S. J., \& Condit, R. (2012). Functional traits explain light and size response of growth rates in tropical tree species. Ecology, 93, 2626-2636. https://doi.org/10.1890/12-0622.1

Sánchez-Salguero, R., Linares, J. C., Camarero, J. J., Madrigal-González, J., Hevia, A., Sánchez-Miranda, Á., Ballesteros-Cánovas, J. A., Alfaro-Sánchez, R., García-Cervigón, A. I., Bigler, C., \& Rigling, A. (2015). Disentangling the effects of competition and climate on individual tree growth: A retrospective and dynamic approach in Scots pine. Forest Ecology and Management, 358, 12-25. https://doi. org/10.1016/j.foreco.2015.08.034

Sanginés de Cárcer, P., Vitasse, Y., Peñuelas, J., Jassey, V. E. J., Buttler, A., \& Signarbieux, C. (2018). Vapor-pressure deficit and extreme climatic variables limit tree growth. Global Change Biology, 24, 11081122. https://doi.org/10.1111/gcb.13973

Schielzeth, H. (2010). Simple means to improve the interpretability of regression coefficients. Methods in Ecology and Evolution, 1, 103-113. https://doi.org/10.1111/j.2041-210X.2010.00012.x

Smith, N. G., Keenan, T. F., Colin Prentice, I., Wang, H., Wright, I. J., Niinemets, Ü., Crous, K. Y., Domingues, T. F., Guerrieri, R., Yoko Ishida, F., Kattge, J., Kruger, E. L., Maire, V., Rogers, A., Serbin, S. P., Tarvainen, L., Togashi, H. F., Townsend, P. A., Wang, M., ... Zhou, S.-X. (2019). Global photosynthetic capacity is optimized to the environment. Ecology Letters, 22, 506-517. https://doi.org/10.1111/ ele.13210

Sullivan, M. J. P., Lewis, S. L., Affum-Baffoe, K., Castilho, C., Costa, F., Sanchez, A. C., Ewango, C. E. N., Hubau, W., Marimon, B., Monteagudo-Mendoza, A., Qie, L., Sonké, B., Martinez, R. V., Baker, T. R., Brienen, R. J. W., Feldpausch, T. R., Galbraith, D., Gloor, M., Malhi, Y., ... Phillips, O. L. (2020). Long-term thermal sensitivity of Earth's tropical forests. Science, 368, 869-874. https://doi. org/10.1126/science.aaw7578

Uriarte, M., Lasky, J. R., Boukili, V. K., \& Chazdon, R. L. (2016). A traitmediated, neighbourhood approach to quantify climate impacts on successional dynamics of tropical rainforests. Functional Ecology, 30, 157-167. https://doi.org/10.1111/1365-2435.12576

Vile, D., Garnier, É., Shipley, B., Laurent, G., Navas, M.-L., Roumet, C., Lavorel, S., Díaz, S., Hodgson, J. G., Lloret, F., Midgley, G. F., Poorter, H., Rutherford, M. C., Wilson, P. J., \& Wright, I. J. (2005). Specific leaf area and dry matter content estimate thickness in laminar leaves. Annals of Botany, 96, 1129-1136. https://doi.org/10.1093/ aob/mci264

Violle, C., Navas, M.-L., Vile, D., Kazakou, E., Fortunel, C., Hummel, I., \& Garnier, E. (2007). Let the concept of trait be functional! Oikos, 116, 882-892. https://doi.org/10.1111/j.0030-1299.2007.15559.x

Violle, C., Thuiller, W., Mouquet, N., Munoz, F., Kraft, N. J. B., Cadotte, M. W., Livingstone, S. W., \& Mouillot, D. (2017). Functional rarity: The ecology of outliers. Trends in Ecology \& Evolution, 32, 356-367. https://doi.org/10.1016/j.tree.2017.02.002

Wagner, F., Rossi, V., Baraloto, C., Bonal, D., Stahl, C., \& Hérault, B. (2014). Are commonly measured functional traits involved in tropical tree responses to climate? International Journal of Ecology, 2014, 389409.

Walker, A. P., Beckerman, A. P., Gu, L., Kattge, J., Cernusak, L. A., Domingues, T. F., Scales, J. C., Wohlfahrt, G., Wullschleger, S. D., \& Woodward, F. I. (2014). The relationship of leaf photosynthetic traits $-\mathrm{V}_{\mathrm{cmax}}$ and $\mathrm{J}_{\max }$-to leaf nitrogen, leaf phosphorus, and 
specific leaf area: A meta-analysis and modeling study. Ecology and Evolution, 4, 3218-3235.

Way, D. A., \& Yamori, W. (2014). Thermal acclimation of photosynthesis: On the importance of adjusting our definitions and accounting for thermal acclimation of respiration. Photosynthesis Research, 119, 89-100. https://doi.org/10.1007/s11120-013-9873-7

Westoby, M. (1998). A leaf-height-seed (LHS) plant ecology strategy scheme. Plant and Soil, 199, 213-227.

Westoby, M., Falster, D. S., Moles, A. T., Vesk, P. A., \& Wright, I. J. (2002). Plant ecological strategies: Some leading dimensions of variation between species. Annual Review of Ecology and Systematics, 33, 125-159. https://doi.org/10.1146/annurev.ecols ys.33.010802.150452

Wickham, H., Averick, M., Bryan, J., Chang, W., McGowan, L., François, R., Grolemund, G., Hayes, A., Henry, L., Hester, J., Kuhn, M., Pedersen, T., Miller, E., Bache, S., Müller, K., Ooms, J., Robinson, D., Seidel, D., Spinu, V., ... Yutani, H. (2019). Welcome to the tidyverse. Journal of Open Source Software, 4, 1686. https://doi.org/10.21105/ joss.01686

Wills, J., Herbohn, J., Hu, J., Sohel, S., Baynes, J., \& Firn, J. (2018). Tree leaf trade-offs are stronger for sub-canopy trees: Leaf traits reveal little about growth rates in canopy trees. Ecological Applications, 28, 1116-1125. https://doi.org/10.1002/eap.1715

Wright, I. J., Dong, N., Maire, V., Prentice, I. C., Westoby, M., Díaz, S., Gallagher, R. V., Jacobs, B. F., Kooyman, R., Law, E. A., Leishman, M. R., Niinemets, Ü., Reich, P. B., Sack, L., Villar, R., Wang, H., \& Wilf, P. (2017). Global climatic drivers of leaf size. Science, 357, 917-921. https://doi.org/10.1126/science.aal4760

Wright, I. J., Reich, P. B., Westoby, M., Ackerly, D. D., Baruch, Z., Bongers, F., Cavender-Bares, J., Chapin, T., Cornelissen, J. H. C., Diemer, M., Flexas, J., Garnier, E., Groom, P. K., Gulias, J., Hikosaka, K., Lamont, B. B., Lee, T., Lee, W., Lusk, C., ... Villar, R. (2004). The worldwide leaf economics spectrum. Nature, 428, 821-827. https://doi org/10.1038/nature02403

Yang, J., Cao, M., \& Swenson, N. G. (2018). Why functional traits do not predict tree demographic rates. Trends in Ecology \& Evolution, 33 , 326-336. https://doi.org/10.1016/j.tree.2018.03.003

Yang, J., Song, X., Cao, M., Deng, X., Zhang, W., Yang, X., \& Swenson, N. G. (2021). On the modelling of tropical tree growth: The importance of intra-specific trait variation, non-linear functions and phenotypic integration. Annals of Botany, 127, 533-542. https://doi. org/10.1093/aob/mcaa085

Yuan, W., Zheng, Y. I., Piao, S., Ciais, P., Lombardozzi, D., Wang, Y., Ryu, Y., Chen, G., Dong, W., Hu, Z., Jain, A. K., Jiang, C., Kato, E., Li, S., Lienert, S., Liu, S., Nabel, J. E. M. S., Qin, Z., Quine, T., ... Yang, S. (2019). Increased atmospheric vapor pressure deficit reduces global vegetation growth. Science Advances, 5, 1-13. https://doi. org/10.1126/sciadv.aax1396

Zambrano, J., Marchand, P., \& Swenson, N. G. (2017). Local neighbourhood and regional climatic contexts interact to explain tree performance. Proceedings of the Royal Society B: Biological Sciences, 284(1855), 20170523. https://doi.org/10.1098/rspb.2017.0523

Zuleta, D., Duque, A., Cardenas, D., Muller-Landau, H. C., \& Davies, S. J. (2017). Drought-induced mortality patterns and rapid biomass recovery in a terra firme forest in the Colombian Amazon. Ecology, 98, 2538-2546. https://doi.org/10.1002/ecy.1950

Zweifel, R., Sterck, F., Braun, S., Buchmann, N., Eugster, W., Gessler, A., Häni, M., Peters, R. L., Walthert, L., Wilhelm, M., Ziemińska, K., \& Etzold, S. (2021). Why trees grow at night. New Phytologist, 231(6), 2174-2185. https://doi.org/10.1111/nph.17552

\section{SUPPORTING INFORMATION}

Additional supporting information may be found in the online version of the article at the publisher's website.

How to cite this article: Bauman, D., Fortunel, C., Cernusak, L. A., Bentley, L. P., McMahon, S. M., Rifai, S. W., AguirreGutiérrez, J., Oliveras, I., Bradford, M., Laurance, S. G. W., Delhaye, G., Hutchinson, M. F., Dempsey, R., McNellis, B. E., Santos-Andrade, P. E., Ninantay-Rivera, H. R., Chambi Paucar, J. R., Phillips, O. L., \& Malhi, Y. (2022). Tropical tree growth sensitivity to climate is driven by species intrinsic growth rate and leaf traits. Global Change Biology, 28, 1414-1432. https:// doi.org/10.1111/gcb.15982 